\title{
Responses to Interpersonal Transgressions in Families: Forgivingness, Forgivability, and Relationship-Specific Effects
}

\author{
William T. Hoyt \\ University of Wisconsin-Madison \\ Michael E. McCullough \\ University of Miami
}

\author{
Frank D. Fincham \\ Florida State University
}

Gregory Maio

Cardiff University

\author{
Joanne Davila \\ State University of New York at Stony Brook
}

\begin{abstract}
Social relations analyses examined the relative importance of forgivingness (disposition to forgive others), forgivability (tendency to obtain forgiveness from others), and relationship effects in determining family members' transgression-related interpersonal motivations (TRIMs) and their perceptions of others' TRIMs toward them (PTRIMs). In 2 studies, the individual and dyadic predictors of these components and their relative importance differed by family role (father, mother, or early adolescent child). Dispositional tendencies accounted for the most variance in father and child forgiveness, whereas mothers' TRIMs and PTRIMs were more strongly determined by relationship and partner effects. Personality correlates of forgivingness and forgivability were moderated by family role. The findings point to the need to embed the study of forgiveness in more complex psychosocial contexts. The theoretical, methodological, and applied implications of this conclusion are discussed.
\end{abstract}

Keywords: forgiveness, family roles, social relations model

There is near-universal agreement among marital and family psychologists about the significance of interpersonal conflict for the well-being of individuals and families. Marital conflict adversely affects spouses' physical (Burman \& Margolin, 1992; Kiecolt-Glazer et al., 1993) and mental health (Beach, Fincham, \& Katz, 1998; Davila \& Bradbury, 1998) as well as children's psychological adjustment (Davies \& Cummings, 1994; Grych \& Fincham, 1990) and physical health (Taylor \& Repetti, 1997; Wickrama, Lorenz, \& Conger, 1997; Wickrama, Lorenz, Conger, \& Elder, 1997). It is also associated with important family outcomes, including poorer parenting (Erel \& Burman, 1995), problematic attachment to parents (Owen \& Cox, 1997), in-

William T. Hoyt, Department of Counseling Psychology, University of Wisconsin-Madison; Frank D. Fincham, Eminent Scholar and Director, Florida State University Family Institute; Michael E. McCullough, Department of Psychology, University of Miami; Gregory Maio, Department of Psychology, Cardiff University, Cardiff, Wales; Joanne Davila, Department of Psychology, State University of New York at Stony Brook.

This study was supported by a grant from the Templeton Foundation.

Correspondence concerning this article should be addressed to William T. Hoyt, Department of Counseling Psychology, University of Wisconsin, 321 Education Building, 1000 Bascom Mall, Madison, WI 53706-1398. E-mail: wthoyt@education.wisc.edu creased parent-child conflict (Margolin, Christensen, \& John, 1996), and conflict between siblings (Brody, Stoneman, \& McCoy, 1994). In addition, conflict predicts both domestic violence (Murphy \& O'Leary, 1989) and divorce (Gottman, 1994).

Because of the significance of conflict for family functioning, researchers have attempted to identify the types of conflict behavior that are most damaging and what drives responses to conflict. Initially studies of behavior were most prominent in understanding conflict and its negative outcomes, but the limitations of a purely behavioral account of conflict soon became apparent. Research consequently expanded to include the study of how cognitions and motivations influence responses to conflict behavior (see Bradbury, Fincham, \& Beach, 2000). For example, it is now well established that the attributions or explanations that partners give for each other's behavior are related to their response to the behavior; across 28 tests of the attribution-behavior association, the mean effect size was $r=$ .34 (Fincham, 2001). Similarly, people who view their partners in a positive light tend to behave in a more supportive fashion toward their partners (Cobb, Davila, \& Bradbury, 2001). Hence, a focus on how people think and feel and on how they believe they will respond to conflict can provide important information on conflict management. 


\section{Transgression-Related Interpersonal Motivations}

Although conflicts in close relationships range from simple divergence in preferences to inconsiderate or irritating acts by one partner to outright acts of betrayal (Rusbult \& Van Lange, 2003), those conflicts that entail feelings of injury and resentment, and attributions of blame, on the part of one or both parties are of primary interest in understanding individual and family functioning (Karremans, Van Lange, Ouwerkerk, \& Kluwer, 2003). We refer to the precipitating causes of these feelings and attendant cognitions as interpersonal transgressions. In this article, we provide a motivational perspective on interpersonal transgressions that has the potential to greatly increase understanding of conflict behavior and family members' responses to conflict by attending to their transgression-related interpersonal motivations (TRIMs).

McCullough and colleagues (McCullough, Bellah, Kilpatrick, \& Johnson, 2001; McCullough et al., 1998; McCullough, Worthington, \& Rachal, 1997) have posited that transgression-related interpersonal motivations vary along three dimensions. People may respond to perceived hurts with increased motivation to avoid their transgressors and with increased motivation to avenge themselves on their transgressors. In addition, they may manifest reduced benevolence motivation (i.e., good will) toward their transgressors.

\section{TRIMs and Willingness to Forgive Following an Interpersonal Transgression}

These three possible TRIMs are also the three dimensions on which forgiveness of the transgressor takes place. That is, when people forgive, they become less avoidant, less vengeful, and more benevolent toward the relationship partner who hurt them (Fincham \& Beach, 2002; McCullough, 2001; McCullough et al., 1997). Consistent with this perspective, Fincham (2000) found that spouses' forgiveness predicted retaliatory and conciliatory behavior following partner transgressions independent of marital quality and the degree of hurt engendered by the transgression.

Because forgiving comprises restoration of these three TRIMs toward their pretransgression levels, we refer to prosocial TRIM ratings (i.e., high levels of Benevolence motivation and low levels of Avoidance and Revenge motivation) as evidence of forgiveness. As discussed in the next section, an important consideration in studying responses to interpersonal transgressions is the appropriate level of analysis. To differentiate among possible determinants of forgiving, we define forgiveness as the offended party's response to a single transgression, forgivingness as the offended party's general disposition to forgive others, and forgivability as the transgressor's general tendency to obtain forgiveness from others.

\section{Level of Analysis}

Research on responses to transgressions - and on willingness to forgive following an interpersonal offense-also needs to address the appropriate level at which forgiveness should be analyzed. As McCullough, Hoyt, and Rachal (2000) noted, forgiveness has usually been treated by both researchers and applied psychologists as synonymous with forgivingness - as a characteristic of the individual (the offended party in a transaction) that is relatively consistent across relationships and across offenses within a given relationship.
When researchers study TRIMs in close relationships, however, they should anticipate that situational and relational factors will contribute to people's willingness to forgive, over and above stable dispositional tendencies. Interpersonal theory suggests that interaction dynamics are influenced by the principle of complementarity: A person's behavior toward an interaction partner is influenced by that partner's recent behavior toward him or her (Leary, 1957; Markey, Funder, \& Ozer, 2003). Longitudinal studies of couple interactions suggest that not only recent but also past partner behaviors play a role, encoded in the form of ongoing expectations or attributions that influence a person's present responses to that partner (Fincham, Harold, \& Gano-Phillips, 2000). Interdependence theory (Rusbult \& Van Lange, 2003) recognizes the multiple causes of behavior in interpersonal interactions with the general formulation that dyadic interaction behaviors $(I)$ are a function of the situation $(S)$ and of the needs, thoughts, and motives of the two interactants $A$ and $B$, or $I=f(S, A, B)$.

In accordance with these theoretical frameworks, research indicates that the extent to which people forgive is influenced not only by the dispositional characteristics of the forgiver, but also by the relationship and by the situation in which the transgression occurs, as well as by the characteristics of the transgressor and the nature of the offense. For example, partners are more likely to forgive when a transgression is judged as having been committed unintentionally (McCullough, Fincham, \& Tsang, 2003; Takaku, Weiner, \& Ohbuchi, 2001) and when it has ceased to have negative consequences for the victim (Mullet \& Girard, 2000). Moreover, people appear to be more willing to forgive relationship partners to whom they are closer and more committed (McCullough et al., 1998; Wieselquist, Rusbult, Foster, \& Agnew, 1999) and partners who apologize (Darby \& Schlenker, 1982; McCullough et al., 1997; Mullet \& Girard, 2000).

Taken together, the effects of such relational and situational factors on forgiveness are likely to be considerable (McCullough $\&$ Hoyt, 2002). For this reason, it behooves researchers to consider the interpersonal context of TRIMs in their research designs and measurement practices, in an effort to elucidate the transactional nature of forgiveness (McCullough \& Hoyt, 2002; McCullough, Hoyt, et al., 2000). In this article, we focus on relational (as opposed to situational) determinants of forgiveness, examining the role of actor, partner, and relationship factors in predicting transgression-relevant motivations.

\section{TRIMs as Psychosocial Phenomena}

A transactional approach to the study of TRIMs suggests two serious omissions in prior research in which forgiveness is implicitly equated with forgivingness. First, even though relational determinants of forgiveness have occasionally been considered, little attention has been paid to the role of the transgressor in determining forgiveness. Are some people simply more forgivable than others? Certainly, the offender's behaviors following an interpersonal transgression (e.g., apology, demonstrations of remorse) is expected to influence the offended party's attributions of culpability (Alicke, 2000), and thereby his or her willingness to forgive. To the extent that some individuals consistently display these relationship-maintaining behaviors more than others, it makes sense to speak of a forgivable personality as well as a forgiving personality. Individual differences in forgivability have important 
implications for forgiveness theory and measurement, as well as for interventions with couples in conflict.

A second, and related, omission concerns the perspective from which forgiveness is viewed; forgiveness has virtually always been measured from the perspective of the offended party, and the transgressor's perception of relational conflicts has rarely been studied (for exceptions, see Kearns \& Fincham, 2005; Stillwell \& Baumeister, 1997). With data on both transgressors' and victims' perceptions, researchers can examine self-other agreement (Kenny, 1994); that is, are persons who claim to be forgiving perceived as forgiving by other family members? In addition, from a transactional perspective, specific transgressions in close relationships occur within the context of an ongoing stream of interaction, with each partner sometimes in the role of offender and other times in the role of victim. The norm of reciprocity, present in all social interactions, may be particularly strong in close relationships (Cotterell, Eisenberger, \& Speicher, 1992), so that perceptions of the partner's typical TRIMs in response to one's own relational misdeeds are likely to be important determinants of reactions to future offenses by the partner. In the present studies, we therefore obtained dyadic ratings of responses to interpersonal transgressions from the perspective of the victim (TRIMs) and also from the perspective of the transgressor (perceived TRIMs [PTRIMs $]$ ). We examined both personal and relational determinants of forgivingness and forgivability, as well as the applicability of the reciprocity hypothesis to transgression-related responses, using the social relations model.

\section{The Social Relations Model}

The social relations model (SRM; Kenny, 1994) is a model of dyadic perceptions and behaviors. It is assumed, for example, that a husband's vengeful feelings toward his wife following an argument are based on four components: the husband's actor effect (i.e., how vengeful the husband typically is toward others), the wife's partner effect (i.e., the extent to which others typically seek to revenge themselves against her following some wrongdoing), the couple's relationship effect (i.e., any reliable deviation from the level of vengefulness that would be expected based on the actor and partner effects), and error. Actor and partner effects are individual-level variables (i.e., they are consistent across relationship partners), whereas the relationship effect, as the name implies, is specific to this dyad. ${ }^{1}$

The effect estimates in SRM reflect variation within families in who tends to forgive and who tends to be forgiven by others. The variances and covariances (between families) among effects are also of interest in social relations analyses. Variance estimates indicate whether there is significant variation between families in, for example, the father's forgivingness or the mother's forgivability. Variance partitioning analyses in this study were conducted on two sets of ratings: one from the perspective of the offended party (TRIMs) and one from the perspective of the offending party (PTRIMs). Thus, there are two variance estimates reflecting between-families variation in dispositional forgivingness: TRIM actor variance reflects variation in self-rated forgivingness-that is, in the person's willingness to forgive other family members on the basis of self-reports of transgression-related motivations. PTRIM partner variance reflects variation in other-rated forgivingness-that is, in the consensus among other family members about a person's perceived willingness to forgive. Similarly, TRIM partner variance and PTRIM actor variance reflect between-family variation in other-rated and self-rated forgivability in family relationships. Table 1 summarizes these correspondences between individual-level variance components and dispositional forgivingness and forgivability.

A novel contribution of the present studies is the examination of dyadic or relationship effects in forgiveness among family members. The TRIM relationship effect reflects the unique propensity of a family member (e.g., the father) to forgive another (e.g., the mother), over and above his actor effect (i.e., typical forgivingness) and her partner effect (i.e., typical forgivability). If there is, as we expect, significant relationship variance in forgiveness motivations, this supports our analysis of forgiveness as a psychosocial phenomenon: It suggests that relational context, as well as individual dispositions, helps to determine people's TRIMs.

Component covariances (reported as correlations) in SRM reflect two levels of reciprocity in perceptions or behaviors. At the individual level, generalized reciprocity (i.e., the extent to which persons who are generally forgiving toward others are also generally forgiven by others) is indexed by the correlation between actor and partner effects; at the relationship level, dyadic reciprocity (i.e., the extent to which persons who uniquely forgive a particular other family member are also uniquely forgiven by that person) is indexed by the correlation between their relationship effects (Kenny \& Nasby, 1980).

\section{Predictors of Forgivingness and Forgivability}

\section{Individual Level}

McCullough and Hoyt (2002) examined forgiveness ratings across a variety of transgressions in close relationships (with friends, parents, and romantic partners) and concluded that some people are dispositionally more willing to forgive than others. Specifically, between $22 \%$ and $44 \%$ of variance in respondents' willingness to forgive a specific transgression was attributable to stable individual differences in forgivingness. Personality factors that best predicted forgivingness in that study were Agreeableness (positively) and Neuroticism (negatively). We theorized that these correspondences have both cognitive and affective roots: Individuals high on Neuroticism differentially attend to negative stimuli (Derryberry \& Reed, 1994), and may have more negative emotional reactions to life stressors (Gunthert, Cohen, \& Armeli, 1999), relative to individuals who are low on Neuroticism. Highly agreeable people are more likely to empathize with a transgressor (Ashton, Paunonen, Helmes, \& Jackson, 1998), and may find forgiveness and reconciliation to be more hedonically pleasant (Côté \& Moskowitz, 1998), relative to less agreeable individuals. In Study 1, we sought to replicate these findings in the context of forgiveness within families, and to explore personality traits underlying forgivability as well as forgivingness.

\footnotetext{
${ }^{1}$ When families are studied, a third level of analysis- that of the family as a whole — can be included in the model. Variance attributable to family effects has been small (although sometimes statistically significant) in published studies of relationship-specific attachment (Cook, 2000) and sense of control (Cook, 1993). Because of this, and because data on three-person families do not contain sufficient degrees of freedom to estimate all components of the family-SRM model, we followed Kashy and Kenny's (1990) recommendation to omit family effects from the model.
} 
Table 1

Interpretation of Actor and Partner Variance for TRIM and PTRIM Ratings

\begin{tabular}{lll}
\hline Role & \multicolumn{1}{c}{ TRIM } & \multicolumn{1}{c}{ PTRIM } \\
\hline $\begin{array}{lll}\text { Actor } \\
\text { Partner }\end{array}$ & $\begin{array}{l}\text { Forgivingness (self-rated) } \\
\text { Forgivability (other rated) }\end{array}$ & $\begin{array}{l}\text { Forgivability (self-rated) } \\
\text { Forgivingness (other rated) }\end{array}$ \\
\hline
\end{tabular}

Note. TRIM = transgression-related interpersonal motivations; PTRIM = perceptions of others' TRIMs.

\section{Relationship Level}

Given the importance of relationship variance in forgiveness motivation as evidence of the psychosocial nature of forgiveness in families, we gave careful attention to predictors of relationship effects in TRIMs and PTRIMs. In their analysis of prosocial behaviors in conflicts in close relationships, Rusbult, Verette, Whitney, Slovik, and Lipkus (1991) identified three classes of relational predictors of people's decision to accommodate rather than retaliate in response to hurtful or thoughtless behavior by a relationship partner: happiness factors, commitment factors, and importance factors. In Study 2, we assessed relationship closeness as representative of the domains of happiness with and importance of the relationship. The construct of commitment is less meaningful in the context of a parent-child relationship than it would be for parent-parent relationships, so we did not attempt to include it. In addition, we included measures of characteristics specifically relevant to the partner's past or typical conflict behaviors. In Study 1 , we hypothesized that willingness to forgive would be a function of (a) perceptions of the other's caring and dependability (trust) and (b) past experience with the constructive or destructive management of conflict in the relationship (ineffective arguing). In Study 2, we again assessed trust, and added a global measure of relationship closeness (based on ratings by all three family members) and a measure of the typical severity of transgressions by the partner, which has been shown to be a mediator of forgivingness (McCullough \& Hoyt, 2002).

\section{Study 1}

We made the following research hypotheses. First, on the basis of our conceptualization of forgiveness as a psychosocial process, we predicted that, in addition to dispositional forgivingness, individual differences in forgivability and relationship-specific motives would account for significant variance in both TRIMs and PTRIMs.

Second, we assessed the extent of self-other agreement at both individual and dyad levels. At the individual level, self-other agreement on a victim's forgivingness is indexed by the correlation of TRIM actor effects with PTRIM partner effects; agreement on an offender's forgivability is indexed by the correlation of PTRIM actor effects with TRIM partner effects. At the dyad level, agreement on the victim's unique forgivingness toward the offender is indexed by the correlation between the victim's relationship effect for TRIM and the offender's relationship for PTRIM for that dyad.

Third, we examined reciprocity correlations for TRIM and PTRIM ratings, to assess the propensity for these motivations and perceptions to evoke like responses from the relationship partner. We hypothesized that persons who report being forgiving will also be regarded by family members as forgivable (positive generalized reciprocity for TRIMs); that persons who report being forgivable will be regarded as forgiving (positive generalized reciprocity for PTRIMs); and that when one member of a dyad is uniquely forgiving (or unforgiving) of the other, this motivational tendency will be reciprocated (positive dyadic reciprocity).

Fourth, because we believe that TRIMs, and perhaps also PTRIMs, are partly dispositional in nature (i.e., consistent across relationships), we examined correlations between self- and otherrated forgivingness and forgivability in the family with self-ratings on five global personality traits (Big Five; Saucier, 1994). On the basis of previous research, we expected that the Big Five dimensions of agreeableness and neuroticism would predict forgivingness. Although no prior research exists on personality correlates of forgivability, it is reasonable to suppose that agreeable individuals, who show high empathy and consideration for others, will be relatively highly forgivable.

Fifth, we examined the extent to which TRIM and PTRIM relationship effects correlated with dyadic ratings of trust in the relationship partner and ineffective arguing. We hypothesized that TRIM relationship effects are partly a function of the relationship context, so that individuals will be uniquely willing to forgive partners whom they trust and with whom they feel conflict discussions are typically constructive. In addition, they are likely to perceive such partners as uniquely forgiving of them (i.e., positive PTRIM relationship effects).

\section{Method}

\section{Participants}

Two-parent families with a daughter in the eighth grade were recruited to participate in a family survey through their schools and through advertisements placed in local media outlets (e.g., newspapers, TV). A total of 96 three-person families participated in the study. Of these, 91 provided complete data for dyadic ratings of forgiveness (TRIMs), and 94 provided complete data for dyadic ratings of perceived forgiveness (PTRIMs). Eligibility criteria included being able to read and comprehend questionnaires and to participate in computer tasks. Families with daughters with severe learning disabilities that would impair their performance were excluded. The girls' average age was 13.24 years $(S D=0.50)$, and $91 \%$ described themselves as Caucasian. Their fathers were 43.1 years old on average $(S D=4.46)$ and predominantly Caucasian $(97 \%)$. Forty-five percent reported graduating high school, and $51 \%$ reported a college or postgraduate education. Mothers were 41.12 years old on average $(S D=$ 4.74) and predominantly Caucasian (98\%). Forty-two percent reported graduating high school, and $57 \%$ reported a college or postgraduate education. Median family income was in the range of $\$ 51,000$ to $\$ 60,000$.

\section{Procedure}

Families were recruited through two means: advertisements in local media requesting families with an eighth-grade daughter to participate in a survey of teen and adult relationships and by sending a letter inviting participation in the study to families with a daughter in the eighth grade at a local school. Interested families were contacted by telephone and invited to visit the laboratory at a time that was convenient to them. During the laboratory visit, each participant completed individual and dyadic measures. Families were paid $\$ 75$ for participation in the study.

\section{Measures}

TRIMs: Dyadic ratings. Each family member rated how he or she typically responds to transgressions by each of the other two family 
members. The TRIM rating scale included 11 items pertaining to the target person's typical reactions in a conflict situation. All items began with the stem "When X angers me or hurts my feelings, I__" and described one possible reaction. Respondents rated how well each description characterized their typical reaction on a 7-point scale (with responses ranging from 1 [strongly disagree] to 7 [strongly agree]). Items were written to exemplify one of three hypothesized TRIM dimensions: Benevolence (3 items; e.g., "Generally don't stay upset with her [him] for long"), Avoidance (4 items; e.g., "Don't want to have anything to do with her [him]"), and Revenge (4 items; e.g., "Find little ways to get back at her [him] for what she [he] did").

Because Benevolence, Avoidance, and Revenge motives have proven to be relatively strongly intercorrelated in previous studies (McCullough \& Hoyt, 2002), we factor analyzed the TRIM items prior to conducting our primary analyses. We found that a single factor accounted for more than $95 \%$ of common factor variance (sum of item communalities; see Russell, 2002), suggesting no evidence of multifactorial structure. We therefore used the factor loadings from this analysis to split the 11 TRIM items into two indicators with comparable loadings onto the single common factor. Internal consistency reliabilities (coefficient alpha) for the two TRIM indicators in the six possible dyads ranged from .76 to .91 , and correlations between indicators ranged from .82 to .91 . Avoidance and Revenge items were reverse scored on these indicators so that higher scores reflect more positive (i.e., forgiving) transgression-related motivations.

PTRIMs: Dyadic ratings. Respondents also rated the two other family members on their perceived motivations toward the respondent following interpersonal transgressions. These ratings used the same 11 items just described, with a modified question stem: "When I anger X or hurt her [his] feelings, she [he] __." Preliminary factor analyses of the PTRIM ratings also suggested that a single factor accounted for the vast majority (95\%) of common factor variance, ${ }^{2}$ so we used the procedure described previously to construct two PTRIM indicators for use in our primary analyses. Coefficient alphas for these indicators in the six possible dyads ranged from .80 to .91 , and correlations between indicators ranged from .79 to .87 .

Ineffective Arguing Inventory (IAI): Dyadic ratings. The IAI (Kurdek, 1994 ) is based on descriptions of ineffective arguing found in the research literature. It comprises eight items (e.g., "Our arguments are left hanging and unresolved") that respondents rate to indicate the extent to which they characterize the relationship with the other person. Kurdek reported high internal consistency for the measure when completed by gay, lesbian, and heterosexual couples (coefficient alphas ranged from .86 to .89) as well as sizable correlations with relationship satisfaction $(r=.62-.71)$. Moreover, the scale was found to be stable over a 1-year period $(r=.63-.84)$ and predicted declines in relationship satisfaction during this period after controlling for initial levels of satisfaction. Internal consistency reliability (coefficient alpha) ranged from .82 to .89 for the six dyads in the present study.

Trust: Dyadic ratings. Participants also recorded their level of trust in relationship with each of the two other family members. For two of the dyads (mother rating father and father rating mother), trust was recorded using a three-item scale. Respondents recorded their level of agreement with three statements (e.g., "I can rely on my partner to keep the promises she [he] makes me") on a 7-point scale (with responses ranging from -3 [strongly disagree] to 3 [strongly agree]). Internal consistency reliabilities (coefficient alpha) were .73 for mothers' ratings of fathers and .79 for fathers' ratings of mothers. Trust ratings for the other four dyads (parentchild and child-parent) were assessed using a single item measuring perceived trust. Participants responded to the question, "How well do you feel [this person] trusts you?" using a 6-point scale (with responses ranging from 1 [not well] to 6 [very, very well]).

Big Five: Self-ratings. Participants rated themselves on the 40 adjectives from Saucier's (1994) Big Five mini-markers. Eight of these items load onto each of five subscales measuring extraversion, neuroticism, agreeableness, conscientiousness, and openness to experience $(\alpha \mathrm{s}=.85$, $.78, .79, .83$, and .70 , respectively).

\section{Social Relations Analyses}

Dyadic ratings of forgiveness and perceived forgiveness were analyzed using the SRM (Kenny \& LaVoie, 1984) adapted for family data (Kashy \& Kenny, 1990). Analyses were conducted with EQS Version 5.7 (Bentler, 1995), using maximum likelihood estimation.

In a three-person family, there are six sets of dyadic ratings (listed in Table 3). These constitute the observed variables that permit estimation of the latent model parameters. For example, TRIM ratings from a daughter toward her father indicate the degree of positive or relationship-enhancing motivations typically felt by the daughter (actor) toward the father (partner) when she has been hurt or angered by him. Variance in these ratings is modeled as a linear combination of four components: an actor effect (how forgiving the daughter typically feels after being hurt by others in the family), a partner effect (how forgiving the others in the family usually feel when hurt by the father), a relationship effect (how uniquely forgiving the daughter typically feels toward her father), and error. Kashy and Kenny's (1990) SRM analysis for a threeperson family is depicted in Figure 1, with error terms (for each measured variable) and paths from the indicators to the corresponding actor and partner effects omitted to avoid clutter. So, for example, ratings for the FM dyad (father's ratings of mother) load onto the F Actr factor and the M Ptnr factor, as well as onto the FM Reln factor, and each of the two FM indicators has an associated error variance, reflecting variance unexplained by these three systematic sources of variance. In these analyses, error terms for a given indicator were permitted to correlate across dyads (also not pictured).

All factor loadings are fixed to one in these models so that variances of the model components may be estimated. Because they share specific factor variance, which is due to shared-item content, errors for a given indicator are allowed to correlate across all six dyads.

\section{Results}

\section{Social Relations Analyses}

Tables 2 and 3 provide individual and dyadic variance estimates, respectively, from the social relations analyses of TRIMs and PTRIMs. Both models fit well: $\chi^{2}(18)=18.33(p>.05)$, Comparative Fit Index $(\mathrm{CFI})=1.00$, root mean square error of approximation $($ RMSEA $)=.01$ for TRIM ratings $(N=273)$; $\chi^{2}(18)=19.62(p>.05), \mathrm{CFI}=.1 .00, \mathrm{RMSEA}=.03$ for PTRIM ratings $(N=282)$.

Individual level: Forgivingness. Table 2 shows raw variance estimates for the individual-level components of SRM (i.e., actor and partner variance for each family member). TRIM actor variance and PTRIM partner effects index individual differences in

\footnotetext{
${ }^{2}$ For both TRIM and PTRIM factor analyses, when data from all dyads were combined, the second eigenvalue was greater than 1.0, suggesting the possibility of an interpretable second factor. Examination of factor loadings for the two-factor solution (after oblique rotation) indicated that, with minimal cross-loading, the first factor comprised all Avoidance and $\mathrm{Be}$ nevolence items plus a single Revenge item ("bears a grudge"), whereas the second factor comprised the remaining three Revenge items. This suggests that Revenge is indeed empirically as well as conceptually distinguishable from Benevolence/Nonavoidance. Nonetheless, although the pattern of findings was consistent for TRIM and PTRIM ratings when all dyads were combined, this pattern was not consistent when dyads were examined separately. Thus, because evidence for this second factor was marginal in our data, as described earlier, and because even in the twofactor solution the factors were highly correlated $(r \mathrm{~s}=.70$ and .59 for TRIM and PTRIM, respectively), the most parsimonious procedure seemed to be to analyze the full TRIM and PTRIM scores. Results of these preliminary factor analyses are available from William T. Hoyt.
} 


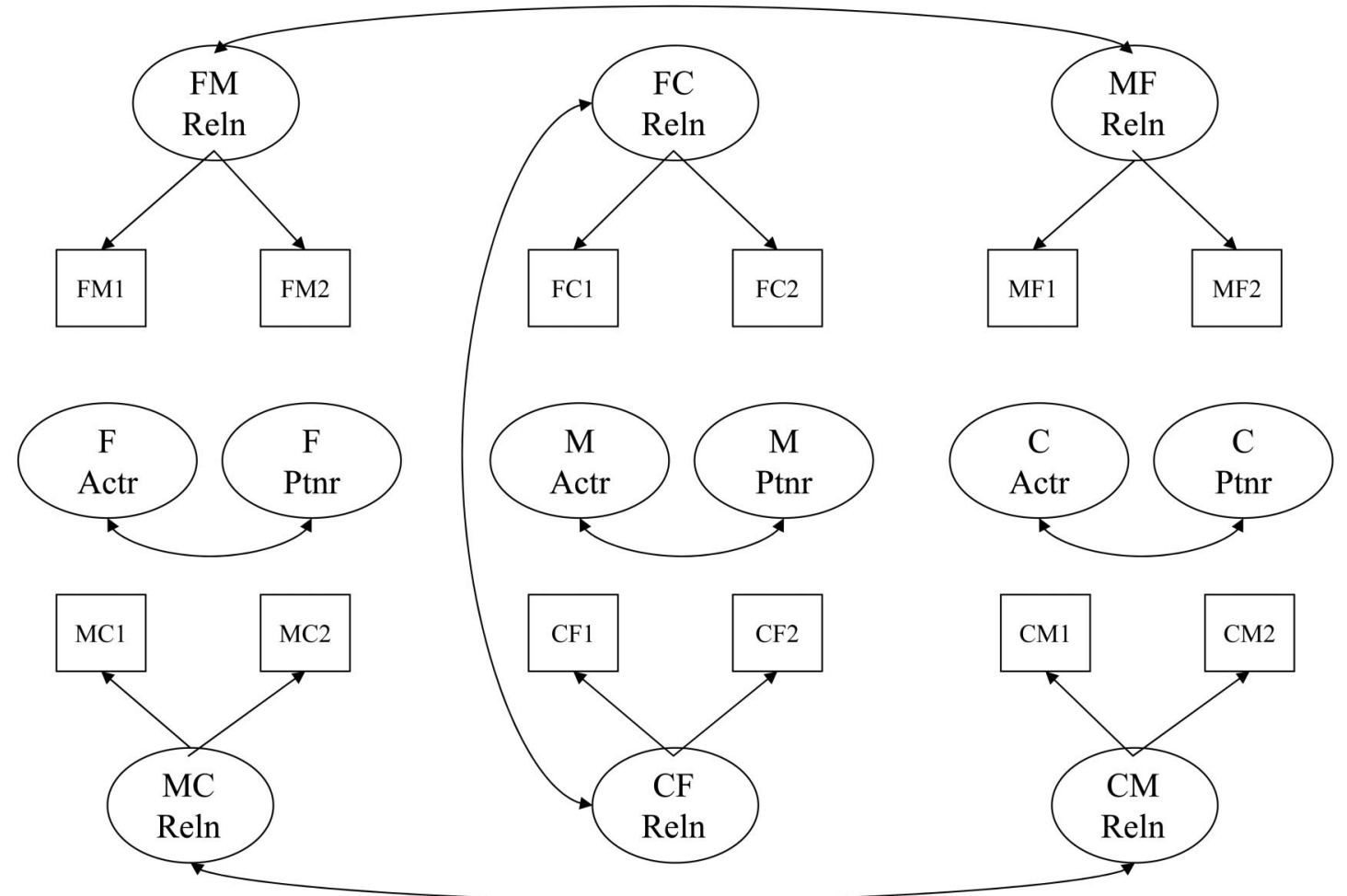

Figure 1. Latent variable model for estimating individual (actor and partner) and dyadic (i.e., relationship) variances from dyadic ratings data. Omitted from the diagram, for clarity, are paths between indicator variables and individual-level factors (e.g., there are paths between F Actr and FM1 and between M Ptnr and FM1), as well as error terms for each indicator variable. Error terms for a given indicator were allowed to correlate across dyads (FM1 is correlated with FC1, MF1, and so on). Correlations between actor and partner effects reflect generalized reciprocity; correlations between relationship effects reflect dyadic reciprocity. $\mathrm{M}=$ mother; $\mathrm{F}=$ father; $\mathrm{C}=$ child; Actr = actor effect; Ptnr = partner effect; Reln = relationship effect.

self-rated and other-rated forgivingness, respectively (refer to Table 1). As seen in Table 2, TRIM actor variance was significant for all three family roles, indicating appreciable variability between families in fathers', mothers' and children's self-reported willingness to forgive. PTRIM partner variance is significant for mothers and children, but not for fathers. Thus, both self-ratings (for all three family roles) and other ratings (for mothers and children) provide evidence of individual differences in forgivingness among members of these three-person families.
To examine self-other agreement, we computed effect estimates for each family member as recommended by Cook and Dreyer (1984), using formulas derived by Warner, Kenny, and Stoto (1979). The correlations between TRIM actor effects and PTRIM partner effects were $.41, .47$, and .45 for fathers, mothers, and children, respectively (all $p \mathrm{~s}<.001$ ), indicating substantial agreement between other ratings and self-ratings for forgivingness. Thus, participants who rated themselves as relatively forgiving were also seen as relatively forgiving by others in their families.

Table 2

Individual-Level Variance Estimates and Reciprocity Correlations, Study 1

\begin{tabular}{lccccccc}
\hline & \multicolumn{3}{c}{ TRIM } & & \multicolumn{3}{c}{ PTRIM } \\
\cline { 2 - 3 } \cline { 7 - 8 } Component & $\begin{array}{c}\text { Actor } \\
\text { variance }\end{array}$ & $\begin{array}{c}\text { Partner } \\
\text { variance }\end{array}$ & $\begin{array}{c}\text { Reciprocity } \\
\text { correlation }\end{array}$ & & $\begin{array}{c}\text { Actor } \\
\text { variance }\end{array}$ & $\begin{array}{c}\text { Partner } \\
\text { variance }\end{array}$ & $\begin{array}{c}\text { Reciprocity } \\
\text { correlation }\end{array}$ \\
\hline Father & $0.52^{*}$ & $0.00^{\mathrm{a}}$ & $.00^{\mathrm{b}}$ & & $0.57^{*}$ & 0.14 & .41 \\
Mother & $0.37^{*}$ & $0.20^{*}$ & $.54^{*}$ & & $0.25^{*}$ & $0.19^{*}$ & -.07 \\
Child & $1.30^{*}$ & $0.22^{*}$ & $.62^{*}$ & & $0.83^{*}$ & $0.31^{*}$ & $.64^{*}$ \\
\hline
\end{tabular}

Note. $n \mathrm{~s}=91$ and 94 for TRIM and PTRIM, respectively. TRIM $=$ transgression-related interpersonal motivation; PTRIM = perceived TRIM.

${ }^{a}$ Negative variance estimate constrained to zero. $\quad{ }^{b}$ Reciprocity correlation set to zero because of absence of partner variance.

$* p<.05$. Significance tests are one-tailed for variance estimates; two-tailed for correlations. 
Table 3

Relationship-Level Variance Estimates and Dyadic Reciprocity Correlations, Study 1

\begin{tabular}{llcllc}
\hline & \multicolumn{2}{c}{ TRIM } & & \multicolumn{2}{c}{ PTRIM } \\
\cline { 2 - 3 } \cline { 5 - 6 } Dyad & $\begin{array}{c}\text { Relationship } \\
\text { variance }\end{array}$ & $\begin{array}{c}\text { Dyadic } \\
\text { reciprocity }\end{array}$ & & $\begin{array}{c}\text { Relationship } \\
\text { variance }\end{array}$ & $\begin{array}{c}\text { Dyadic } \\
\text { reciprocity }\end{array}$ \\
\hline FM & 0.19 & .11 & & $0.50^{*}$ & .37 \\
FC & 0.03 & -.02 & & 0.21 & .08 \\
MF & $1.13^{*}$ & .11 & & $0.73^{*}$ & .37 \\
MC & $0.00^{\mathrm{a}}$ & $.00^{\mathrm{b}}$ & & $0.47^{*}$ & $.00^{\mathrm{b}}$ \\
$\mathrm{CF}$ & $0.19^{*}$ & -.02 & & 0.16 & .08 \\
$\mathrm{CM}$ & 0.06 & $.00^{\mathrm{b}}$ & & $0.00^{\mathrm{a}}$ & $.00^{\mathrm{b}}$ \\
\hline
\end{tabular}

Note. $n \mathrm{~s}=91$ and 94 for TRIM and PTRIM, respectively. TRIM = transgression-related interpersonal motivation; PTRIM = perceived TRIM; FM = father's ratings of mother; FC = father's ratings of child; $\mathrm{MF}=$ mother's ratings of father; $\mathrm{MC}=$ mother's ratings of child; $\mathrm{CF}=$ child's ratings of father; $\mathrm{CM}=$ child's ratings of mother.

${ }^{a}$ Negative variance estimate constrained to zero. ${ }^{\mathrm{b}}$ Reciprocity correlation set to zero because of absence of relationship variance.

$* p<.05$. Significance tests are one-tailed for variance components; two-tailed for correlations.

Individual level: Forgivability. Another possible determinant of people's willingness to forgive a specific transgression is the forgivability of the transgressor. PTRIM actor variance and TRIM partner variance index individual differences in self-reported and other-reported forgivability, respectively (refer to Table 1). As seen in Table 2, PTRIM actor variance was significant for all three family roles, indicating substantial variance in fathers', mothers', and children's self-reported forgivability. TRIM partner variance was significant for mothers and children, but not for fathers. Self-other agreement on forgivability was significant, with correlations between PTRIM actor and TRIM partner effects of $r=.35$, .23 , and .53 for fathers, mothers, and children, respectively (all $p s<.05)$. Thus, participants who experienced receiving high levels of forgiveness from others were also rated as relatively forgivable by their families. (Note that because father partner variance was nonsignificant for both TRIMs and PTRIMs, selfother agreement correlations for fathers on both forgivingness and forgivability should be interpreted with caution.)

Individual level: Reciprocity. Reciprocity at the individual level reflects a correlation between actor effects and partner effects for a given set of ratings (TRIM or PTRIM). When either actor or partner variance is negligible, the generalized reciprocity correlation will be negligible as well. As shown in Table 2, for TRIMs, generalized reciprocity was evident for both mothers and children. That is, mothers and children who rated themselves as more forgiving tended to be forgiven in turn by other family members. It is not unexpected that generalized reciprocity was nonsignificant for fathers, given that father partner variance was also nonsignificant and negligible. For PTRIMs, children again showed significant reciprocity, indicating that children who reported receiving forgiveness from family members were more likely to be perceived by those family members as forgiving.

Relationship level: Forgiving and being forgiven. Table 3 shows relationship variance and dyadic reciprocity correlations for TRIM and PTRIM ratings. Relationship effects reflect a unique propensity to forgive the other person (or to perceive her or him as forgiving), beyond what would be expected given the rater's actor effect and the other's partner effect for that variable. For both
TRIMs and PTRIMs, mother's ratings of fathers (MF dyads) showed significant evidence of relationship variance. CF ratings also demonstrated significant relationship variance for TRIMs, as did FM and MC ratings for PTRIMs. In the remaining dyads, there was no evidence of significant stable variance not accounted for by the relevant actor and partner effects. Despite the lack of significant relationship variance for some dyads, self-other agreement at the dyadic level was significant and substantial for all dyads, with $r$ s ranging from .72 to .84 , all $p$ s $<.001$.

Relationship level: Reciprocity. Reciprocity at the relationship (dyadic) level is indexed by correlated relationship effects. For example, a significant dyadic reciprocity correlation between mothers and fathers indicates that mothers who are uniquely willing to forgive their spouses (MF relationship effect) are also uniquely forgiven by their spouses (FM relationship effect). As shown in Table 3, there was no evidence of dyadic reciprocity in either TRIM or PTRIM ratings.

Percentage of variance (by dyad). As an aid to interpretation of the variance estimates in Tables 2 and 3, we computed the percentage of construct (i.e., reliable) variance accounted for by each component of the model. Because actor and partner variance estimates differ for different roles (and relationship variance estimates differ for different dyads) in SRM analyses of family data, this relative variance partitioning differs for each dyad. Similar to proportion of variance estimates in other generalizability studies, these analyses indicate the relative importance of each SRM component in each of the six dyads.

Figure 2 shows the percentage of construct variance attributable to actor, partner, and relationship for TRIM ratings. Note that the importance of each component varies depending on the makeup of the dyad. For all but the MF dyad, actor variance represents greater than $50 \%$ of stable TRIM variance. For children especially (CM and CF dyads), the vast majority (more than $80 \%$ ) of the construct variance in TRIM ratings is actor variance: If children are forgiving toward one parent, they are very likely to be forgiving toward the other.

In MF dyads, by contrast, relationship variance is the major determinant of TRIMs, indicating that wives' reactions to husbands' transgressions are determined to a large extent by relationship-specific factors, rather than by individual tendencies (stable across different relationships) toward forgivingness or forgivability. Finally, for parent-child dyads (FC and MC), the proportion of partner variance is substantial (about 30\%), indicating that motivations in these relationships are partly a function of the perceived forgivability of the child.

Figure 3 shows the comparable estimates of percentage of construct variance for the PTRIM ratings. Comparing Figures 2 and 3 , it can be seen that PTRIM ratings contain less actor variance (on average) than do TRIM ratings. Although people's motivations in response to others' transgressions (TRIMs) may be relatively stable across different relationship partners, their perceptions of others' motivations toward them (PTRIMs) are to a greater extent a function of partner and relationship effects. Still, children's perceptions of their parents' forgivingness are relatively consistent, with more than $70 \%$ of variance attributable to actor (i.e., stable tendencies to perceive others as forgiving).

In parent-parent dyads, relationship variance was an important component of PTRIMs (and more so for MF ratings than FM) Especially for mothers, feeling forgiven by a spouse is not primarily a function of mothers' (self-rated) forgivability, nor of fathers' 
Study 1 TRIM Variance Partitioning (by Dyad)

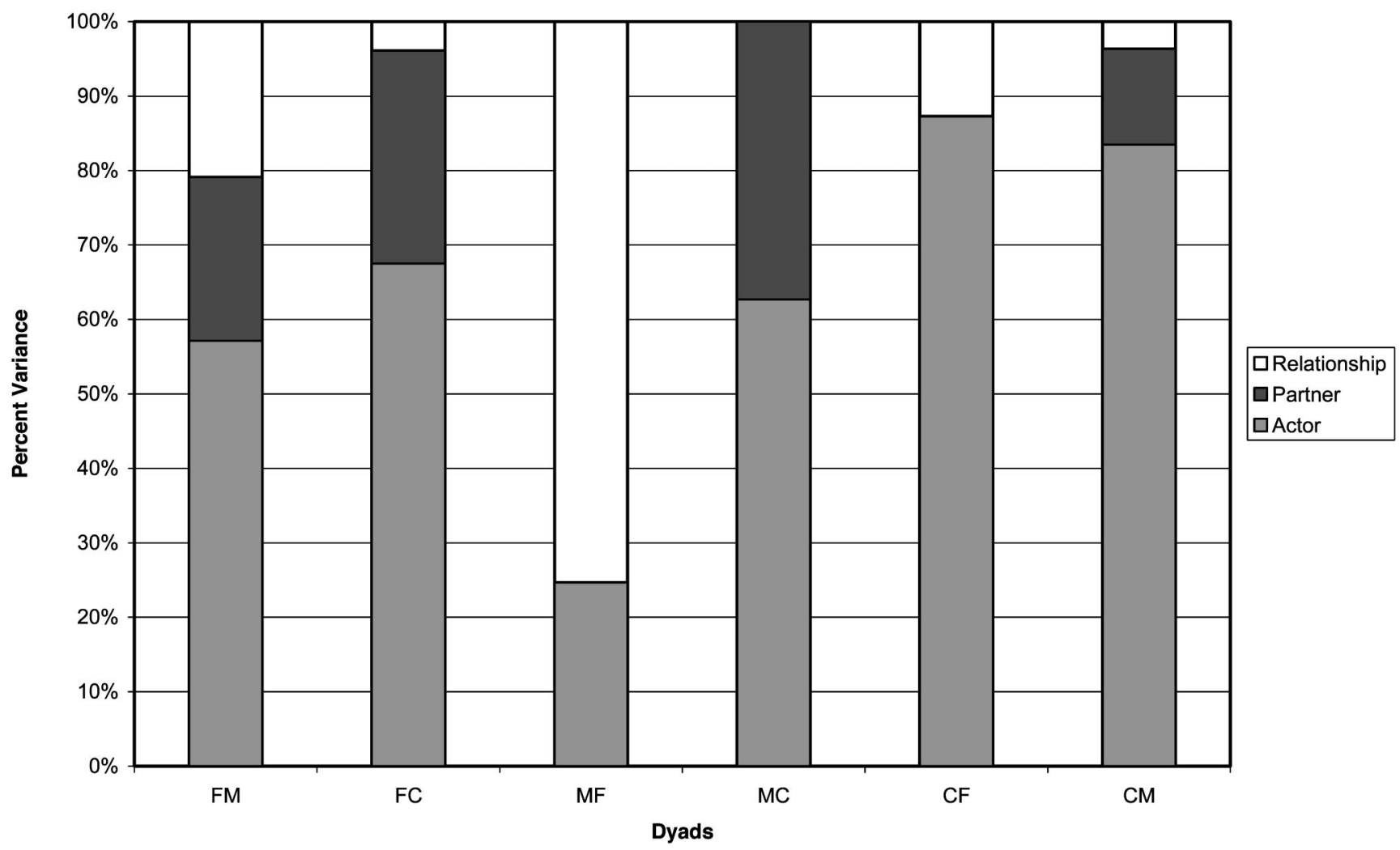

Figure 2. Percentage of variance in Study 1 TRIMs attributable to actor, partner, and relationship effects, by dyad. TRIMs $=$ transgression-related interpersonal motivations.

(other-rated) forgivingness, but rather of relationship-level factors. $\mathrm{MC}$ ratings also showed strong evidence of relationship variance.

\section{Personality Correlates of Forgivingness and Forgivability}

We examined the extent to which self- and other-rated forgivingness and forgivability were associated with self-rated personality traits by correlating SRM actor and partner effect estimates with self-ratings on the Big Five for each family role (father, mother, and child). As indicated in Table 1, the actor effect reflects the extent to which the rater sees him- or herself as generally forgiving (TRIM) or as generally forgiven or forgivable (PTRIM), relative to other family members. The partner effect reflects the extent to which others perceive the target person as forgivable (TRIM) or forgiving (PTRIM).

Table 4 reports multiple correlations and statistically significant standardized regression weights from the regression of TRIM components on self-rated personality traits. In general, self-ratings of both forgivingness and forgivability (i.e., actor effects) were significantly associated with self-ratings of personality, other ratings of forgivability were not well predicted, and other ratings of forgivingness were moderately associated with personality ratings.

Regression weights in Table 4 indicate the specific personality dimensions that uniquely predict TRIM and PTRIM effects. Neuroticism and Agreeableness tended to be related to both forgivingness and forgivability in the directions predicted (i.e., negatively for Neuroticism and positively for Agreeableness), but they did not uniquely contribute to prediction of all TRIM and PTRIM effects for all family members. Extraversion was not predictive of either forgivingness or forgivability. The salience of the remaining personality dimensions (Conscientiousness and Openness to Experience) differed by role. Mothers' Conscientiousness was negatively related to otherratings of both forgivingness and forgivability, and also marginally related to self-rated forgivingness $(p<.10)$. For children, on the other hand, Conscientiousness was positively related to self-rated forgivingness and forgivability; for fathers, it was positively associated with other-ratings of forgivingness. The differential correlations with other-ratings for the two parents are particularly strong evidence of the differential valence of this trait for the two roles: More conscientious fathers were more readily forgiven, whereas more conscientious mothers were less likely to be forgiven and were also perceived as less forgiving, relative to those low on this trait.

Finally, Openness to Experience was (unexpectedly) negatively associated with both forgivingness and forgivability for fathers, but not for mothers or children. Thus, fathers rating themselves as more creative and intellectual were less likely to perceive others as forgiving, and also rated themselves (and were rated by others) as less forgiving of other family members, compared with those scoring lower on this trait. This was not the case for mothers or children, for whom the associations between Openness to Experience and forgiveness tended to be positive (albeit nonsignificant) or near zero. 
Study 1 PTRIM Variance Partitioning (by Dyad)

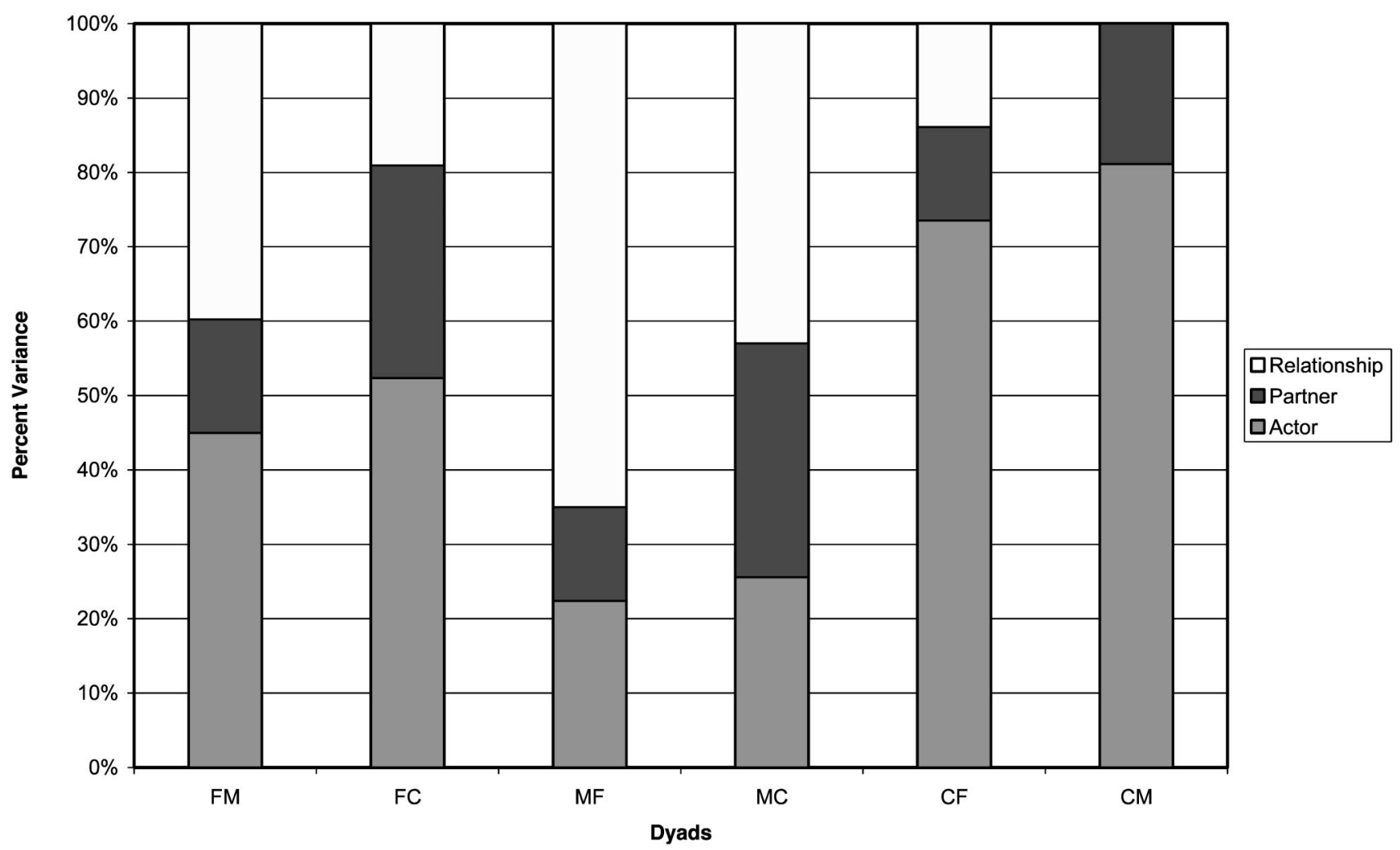

Figure 3. Percentage of variance in Study 1 PTRIMs attributable to actor, partner, and relationship effects, by dyad. PTRIMs $=$ perceived transgression-related interpersonal motivations.

\section{Dyadic Correlates of Unique TRIMs and PTRIMs}

Relationship effects for a given dyad indicate unique motivations toward (or perceptions of) the relationship partner after accounting for the perceiver's actor effect and the target's partner effect. For example, the TRIM relationship effect for father's ratings of mother in a given family reflects the father's unique willingness to forgive the mother, over and above what would be expected given the father's actor effect and the mother's partner effect. The corresponding PTRIM relationship effect indicates his unique perceptions of her willingness to forgive him, again controlling for the relevant actor and partner effects. We hypothesized that unique (relationship-level) TRIMs and PTRIMs both arise from and give rise to the respondent's perceptions of the nature of the relationship, specifically his or her perceptions of the constructive or destructive management of conflict in the relationship (ineffective arguing) and his or her perceptions of the level of trust in the relationship.

We tested this hypothesis by regressing each family member's unique TRIMs and PTRIMs vis-à-vis each relationship partner onto global relational perceptions (ineffective arguing and trust) for that dyad (see Table 5).

The two relational variables accounted for significant variance in TRIM relationship effects (left side of Table 5), with $R^{2}$ ranging from .12 to .38 for the six dyads. Ineffective arguing was a consistently strong (and significant) predictor of unique TRIMs for all dyads, with higher perceptions of ineffective arguing associated with lower willingness to forgive. Trust was less important in predicting unique TRIMs, but made a significant contribution for both $\mathrm{CM}$ and $\mathrm{MC}$ dyads.

Associations between these dyadic variables and relationship effects for PTRIMs were similar in magnitude to those for TRIMs: $R^{2}$ ranged from .20 to .36 (right side of Table 5). Here, too, ineffective arguing was a consistently strong (and significant) predictor, with trust contributing significantly only for FC and CM dyads.

Thus, both unique willingness to forgive a partner (unique TRIMs) and unique perceptions of being forgiven by that partner (unique PTRIMs) are strongly related to perceptions of constructive norms for dealing with conflict in that relationship. When past experiences of conflict with a relationship partner have been aversive (high scores on IAI), the person is likely to feel neither forgiving toward nor forgiven by that partner in future conflicts. When these specific perceptions of past conflict behaviors are statistically controlled, global perceptions of trust in the partner are not strongly predictive of unique transgression-related motivations or perceptions.

\section{Discussion}

Although measures of forgiveness have often been treated as indicators of dispositional forgivingness in the offended party, our 
Table 4

Standardized Regression Coefficients ( $\beta$ ) Predicting Forgivingness and Forgivability From Big Five Self-Ratings, Study 1

\begin{tabular}{|c|c|c|c|c|}
\hline \multirow[b]{2}{*}{ Factor } & \multicolumn{2}{|c|}{ Forgivingness } & \multicolumn{2}{|c|}{ Forgivability } \\
\hline & $\begin{array}{c}\text { Self-rated } \\
\text { (TRIM actor) }\end{array}$ & $\begin{array}{c}\text { Other rated } \\
\text { (PTRIM partner) }\end{array}$ & $\begin{array}{c}\text { Self-rated } \\
\text { (PTRIM actor) }\end{array}$ & $\begin{array}{c}\text { Other rated } \\
\text { (TRIM partner) }\end{array}$ \\
\hline \multicolumn{5}{|c|}{ Father } \\
\hline Extraversion & - & - & - & - \\
\hline Neuroticism & $-.28 *$ & - & $-.24 *$ & - \\
\hline Agreeableness & - & $.21 \dagger$ & - & - \\
\hline Conscientiousness & - & - & - & $.23 *$ \\
\hline Openness & $-.21 *$ & $-.21 \dagger$ & $-.35 * *$ & - \\
\hline Multiple $R$ & $.41 *$ & $.32 \dagger$ & $.43^{*}$ & .29 \\
\hline \multicolumn{5}{|c|}{ Mother } \\
\hline Extraversion & - & - & - & - \\
\hline Neuroticism & $-.22 \dagger$ & - & - & - \\
\hline Agreeableness & $.22 \dagger$ & $.26^{*}$ & - & - \\
\hline Conscientiousness & $-.17 \dagger$ & $-.25 *$ & - & $-.25^{*}$ \\
\hline Openness & - & - & - & - \\
\hline Multiple $R$ & $.38^{*}$ & $.41^{*}$ & .20 & .31 \\
\hline \multicolumn{5}{|c|}{ Children } \\
\hline Extraversion & - & - & - & - \\
\hline Neuroticism & - & - & $-.22 *$ & - \\
\hline Agreeableness & $.40 * *$ & - & - & - \\
\hline Conscientiousness & $.22 *$ & - & $.23 *$ & - \\
\hline Openness & - & - & $.20 \dagger$ & - \\
\hline Multiple $R$ & $.58 * *$ & .32 & $.54 * *$ & .23 \\
\hline
\end{tabular}

Note. All predictors were entered simultaneously in 12 separate multiple regression analyses. $n \mathrm{~s}=273$ and 282 for TRIM and PTRIM, respectively. Dashes indicate nonsignificant $\beta(p \geq .10)$. TRIM $=$ transgression—related interpersonal motivation (self forgives other); PTRIM = perceived TRIM (other forgives self).

$\dagger p<.10 . \quad * p<.05 . \quad * * p<.001$, two-tailed.

findings suggest that this interpretation is an oversimplification. As shown in Figure 2, dispositional forgivingness motives (i.e., TRIM actor effects) are a strong determinant of child-parent TRIMs, account for something like one half to two thirds of the variance in parent-child or husband-wife TRIMs, and are a somewhat less important determinant of wives' TRIMs toward husbands. PTRIM partner variance provides evidence of modest consensus among family members on the dispositional forgivingness of mothers and

Table 5

Summary of Results From Hierarchical Regressions Predicting TRIM and PTRIM Relationship Effects From Relational Variables, Study 1

\begin{tabular}{|c|c|c|c|c|c|c|}
\hline \multirow[b]{3}{*}{ Dyad } & \multicolumn{3}{|c|}{ TRIM } & \multicolumn{3}{|c|}{ PTRIM } \\
\hline & \multirow[b]{2}{*}{$R$} & \multicolumn{2}{|c|}{$\begin{array}{c}\text { Standardized } \\
\text { coefficient }\end{array}$} & \multirow[b]{2}{*}{$R$} & \multicolumn{2}{|c|}{$\begin{array}{c}\text { Standardized } \\
\text { coefficient }\end{array}$} \\
\hline & & IA & TRU & & IA & TRU \\
\hline FM & $.34 *$ & $-.30 *$ & .09 & $.45^{* *}$ & $-.43^{* *}$ & .05 \\
\hline FC & $.41^{* *}$ & $-.31^{*}$ & .16 & $.60 * *$ & $-.43^{* *}$ & $.27 *$ \\
\hline MF & $.46^{* *}$ & $-.43 * *$ & .07 & $.45 * *$ & $-.40^{* *}$ & .10 \\
\hline MC & $.56^{* *}$ & $-.36^{*}$ & $.25^{*}$ & $.56 * *$ & $-.35^{*}$ & $.27 *$ \\
\hline $\mathrm{CF}$ & $.62 * *$ & $-.58 * *$ & .08 & $.59 * *$ & $-.50 * *$ & .15 \\
\hline $\mathrm{CM}$ & $.55^{* *}$ & $-.37 * *$ & $.24 *$ & $.47 * *$ & $-.43^{* *}$ & .07 \\
\hline
\end{tabular}

Note. Sample sizes vary from 88 to 94 because of missing data. TRIM $=$ transgression-related interpersonal motivation; PTRIM = perceived TRIM; IA = ineffective arguing; TRU = trust; FM = father's ratings of mother; $\mathrm{FC}=$ father's ratings of child; $\mathrm{MF}=$ mother's ratings of father; $\mathrm{MC}=$ mother's ratings of child; $\mathrm{CF}=$ child's ratings of father; $\mathrm{CM}=$ child's ratings of mother.

$* p<.05$. ** $p<.001$, two-tailed. 
children, but not of fathers (see Table 2), and these partner effects agree reasonably well with the target person's self-ratings (TRIM actor effects). In addition to dispositional forgivingness, our findings suggest that both dispositional forgivability and relationship effects are important determinants of dyadic forgiveness motives in families.

\section{Evidence for Variability in Forgivability and Relationship Effects}

We also found support for consistent individual differences in forgivability (i.e., some people are consistently more likely to be forgiven than others) within families: This consistency was evident in family members' self-ratings (i.e., PTRIM actor variance), and also in the consistency with which other family members reported forgiving them (TRIM partner variance-again significant for mothers and children but not for fathers). As in the case of ratings of forgivingness, other ratings and self-ratings of forgivability showed moderate-to-strong convergence, indicating that family members who reported being forgiven by others generally were.

The importance of relational (or unique) motivations and perceptions differed for different dyads in this sample. Motivation to forgive (TRIMs) was mostly a function of actor and partner variance, except for MF dyads. The predominance of relationship variance in this dyad reflects that mothers' willingness to forgive their spouses is not well predicted from their propensity to forgive their children, nor from children's willingness to forgive fathers. Relationship variance was somewhat more prevalent in PTRIMs, indicating that relational determinants play a somewhat greater role in the experience of feeling forgiven by other family members than in the willingness to forgive them. (The exception here was child-parent dyads, in which PTRIMs were primarily or completely a function of actor and partner variance.)

\section{Reciprocity}

There was some evidence of reciprocity at the individual level, particularly for children. Children who reported being forgiving (TRIM) tended to be forgiven by their parents in turn. Similarly, children who perceived parents as forgiving (PTRIM) were perceived by their parents as forgiving. Finally, mothers showed significant generalized reciprocity on TRIMs (but not on PTRIMs).

Although there was significant relationship variance in parentparent dyads, there was no evidence of dyadic reciprocity among spouses. For example, there was no evidence that when wives are uniquely forgiving of their husbands (TRIM), their husbands tend to be uniquely forgiving of them in return.

\section{Predicting Individual Effects}

As expected, self-rated Neuroticism tended to be negatively associated with TRIMs and PTRIMs, and self-rated Agreeableness was a positive (albeit not always significant) predictor of these motivations and perceptions. A surprising finding was the differential association of two personality dimensions (Conscientiousness and Openness to Experience) with forgiveness for different family members. In the case of conscientiousness, it may be that core traits associated with this factor (e.g., thoroughness, efficiency, accountability for one's actions) are perceived differently vis-à-vis the typical parenting roles of mothers and fathers. John
(1990) associated the Big Five dimension of conscientiousness with the Q-sort dimension of ego control (Block \& Block, 1980), which implies an overly fastidious and simplistic orientation to interpersonal relationships and a tendency to contain rather than express emotions and motivations. A high degree of ego control may be incongruent with the prototypically nurturing role of mothers, such that more conscientious mothers tend to be perceived as less forgiving and forgivable. The congruence of a controlling and orderly orientation with the provide-and-protect role of fathers may account for the positive association with forgivability for this family role.

It is less obvious why Openness to Experience should be strongly negatively associated with self-rated forgiveness for fathers, but not for other family members. One possible explanation is that Openness to Experience for men connotes an intellectual orientation tinged with cynicism, such that men scoring higher on this dimension perceive self and others as less strongly connected, and therefore, among other things, less forgiving and forgivable. We know of no evidence to suggest gender differences in correlations between Openness to Experience and other relational variables, but the present findings suggest that further research on this question is warranted.

\section{Predicting Relationship Effects}

Both TRIM and PTRIM relationship effects were well predicted by ratings on the IAI, which reflect typical patterns of arguing in the dyad as perceived by one member of that dyad. Negative associations with IAI scores were moderate to strong in magnitude for both TRIM and PTRIM relationship effects, indicating that family members were less likely to forgive another, and to perceive the other as forgiving, when they recalled a history of ineffective argumentation with that person.

Although trust did not contribute significantly to predicting TRIM or PTRIM relationship effects for most dyads once IAI scores were statistically controlled, this lack of association is in part a function of overlap between the two predictors (median $r=$ -.50 across the six dyads), and may also reflect attenuation that is due to the unreliability of the single-item measure used for four of the dyads. Presumably, IAI scores reflect unconstructive conflict behaviors that are one determinant of trust in a relationship partner and are also strongly relevant to forgiveness motives.

\section{Limitations}

Families were predominantly Caucasian middle-class families with a daughter in the eighth grade living in the United States. It is unclear to what extent these findings would generalize to a more diverse sample, to families from another country or culture, or to families in which a son rather than a daughter was the target child. It is conceivable that the high proportion of actor variance (and almost no variance in relationship effects) for children in this study was a function of their gender (women), their developmental stage (early adolescence), or both.

\section{Study 2}

To address the question of generalizability of findings obtained in Study 1, and to better examine theoretical predictors of relationship effects, we studied TRIMs and PTRIMs in a second set of 
families residing in a different country, and included adolescent boys and girls as participants. Specifically, we examined the extent to which other global relationship characteristics predict TRIMs. Thus, in Study 2 we omitted the IAI and focused instead on an improved measure of trust and on a dyadic measure of relationship closeness that incorporates qualities thought to predict accommodative responses (i.e., relationship satisfaction and importance).

To address whether feelings of closeness and trust allay natural motivations of revenge or avoidance in response to interpersonal hurt, we included an additional variable assessing the seriousness of typical transgressions by that relationship partner (transgression severity). Because reciprocity may be an important norm in close relationships (with negative reciprocity showing special importance in distressed relationships; Epstein, Baucom, \& Rankin, 1993; Gottman, 1998), transgression severity should be a strong predictor of TRIMs (McCullough \& Hoyt, 2002). If dyadic variables such as trust and closeness modify people's motivational reactions to transgressions in close relationships, we would expect these variables to predict incremental TRIM variance, after controlling for transgression severity.

We made the following research hypotheses. First, we sought to replicate the Study 1 finding that, in addition to dispositional forgivingness, individual differences in forgivability and relationship-specific motives would account for significant variance in both TRIMs and PTRIMs.

Second, we again examined self-other agreement for forgivingness and forgivability, to determine whether each person's own view of her or his standing on these constructs was corroborated by other family members.

Third, we again predicted significant positive reciprocity correlations for both TRIM and PTRIM ratings, at both the individual and dyadic levels.

Fourth, although we did not replicate our analyses of individual level predictors, we augmented our analysis of relationship-level predictors to determine whether broad feelings and attitudes about one's relationship partner (trust and closeness) would predict TRIM and PTRIM relationship effects even after controlling for transgression-specific feelings and attitudes (i.e., transgression severity). We predicted that dyadic closeness and trust would be significantly associated with relationship effects on both TRIMs and PTRIMs, after controlling for general transgression severity.

\section{Method}

\section{Participants}

Participants were two parents and one child from 79 families living in a medium-sized metropolitan area in South Wales. They were recruited through visits to schools, newspaper advertising, and leaflets. Both parents had been living together for at least the last 5 years $(M=21$ years and 4 months; $S D=5$ years and 7 months), and the children (31 boys and 48 girls) were between 12 and 14 years of age. The fathers' average age was 44.77 years $(S D=0.75)$, and the mothers' average age was 42.93 years $(S D=0.75)$. The parents' average joint annual income was $£ 38,691$ (approximately, \$59,000 USD; $S D=£ 16,714$ ), and thus fell within the range of middle-class income.

\section{Procedure}

Family members arrived at the lab together, but completed the questionnaires in separate rooms. Each participant completed measures of their perceptions of the closeness of each relationship among the three family members who attended the lab session. Participants also completed measures of trust, transgression severity, and forgiveness in their relationships with the two other family members. After completing these questionnaires, participants were fully debriefed and thanked for their participation.

\section{Measures}

TRIMs and PTRIMs. Dyadic ratings of TRIMs and PTRIMs were reported using the same 11-item scales used in Study 1. As in Study 1, a factor analysis indicated that both scales were unidimensional, and we used these factor analytic results to construct two indicators for each construct, as described previously. Coefficient alphas for these indicators ranged from .51 to .82 for TRIMs and from .68 to .87 for PTRIMs in the six dyads. Correlations between indicators ranged from .75 to .86 for TRIMs and from .73 to .86 for PTRIMs.

Trust. Participants reported on level of trust with each family member by responding to four items rating the others (a) willingness to "be on my side," (b) honesty and openness, (c) caring, and (d) willingness to discuss problems in the relationship (e.g., "I believe that [family member] is generally pretty honest and open with me") on a 5-point rating scale (with responses ranging from 1 [never] to 5 [very often]), with higher scores reflecting stronger trust. Coefficient alphas ranged from .71 to .86 for the six dyads.

Closeness. Participants reported the level of closeness in each of the three relationships (mother-child, father-child, and father-mother), so closeness ratings were (a) relational, rather than dyadic, and (b) based on the perspectives of all three family members, not just the two in the relationship. The four closeness items included one item assessing enjoyment of time spent together, two items assessing the importance of the relationship to each of the parties involved, and one item directly assessing relationship closeness. So, for example, each of the two members of a dyad responded to the question stem "How much do you enjoy the time you spend together" [underlining in original], whereas the third family member responded to "How much do they enjoy the time they spend together?" Participants rated each item on a 5-point scale with anchors that varied for each item, with a response of 1 (little enjoyment, importance, or closeness) and 5 (much enjoyment, importance, or closeness). Thus, higher scores reflected greater closeness. Coefficient alphas ranged from .79 to .94 for the nine sets of ratings ( 3 raters $\times 3$ relationships). Closeness scores were then computed by taking the mean of the three perspectives for each relationship.

Transgression severity. Participants rated frequency of severe transgressions by each other family member by responding to four items-(a) can be very annoying, (b) can say and do some pretty hurtful things, (c) I have felt wounded by other person, and (d) has done things that really hurt me (e.g., "Sometimes [family member] has done things that really hurt me")- on a 5-point rating scale (with responses ranging from 1 (never) to 5 (very often), with higher scores representing greater frequency of feeling seriously hurt by that person. Coefficient alphas ranged from .74 to .86 for the six dyads.

\section{Analyses}

As in Study 1, we computed variance estimates and reciprocity correlations with EQS 5.7 (Bentler, 1995), using maximum likelihood estimation (see Figure 1). To examine self-other agreement and predictors of relationship effects, we computed effect estimates using Warner et al.'s (1979) formulas to use as dependent variables in regression analyses.

\section{Results}

\section{Social Relations Analyses}

As in Study 1, the fit of the SRM model to the data was very good for both TRIM ratings $\left[\chi^{2}(18)=16.99, p>.05, \mathrm{CFI}=1.00\right.$, 
Table 6

Individual-Level Variance Estimates and Reciprocity Correlations, Study 2

\begin{tabular}{lcccccccc}
\hline & \multicolumn{3}{c}{ TRIM } & & \multicolumn{3}{c}{ PTRIM } \\
\cline { 2 - 3 } Component & $\begin{array}{c}\text { Actor } \\
\text { variance }\end{array}$ & $\begin{array}{c}\text { Partner } \\
\text { variance }\end{array}$ & $\begin{array}{c}\text { Reciprocity } \\
\text { correlation }\end{array}$ & & $\begin{array}{c}\text { Actor } \\
\text { variance }\end{array}$ & $\begin{array}{c}\text { Partner } \\
\text { variance }\end{array}$ & $\begin{array}{c}\text { Reciprocity } \\
\text { correlation }\end{array}$ \\
\hline Father & $0.47^{*}$ & $0.45^{*}$ & $.37^{*}$ & & $0.63^{*}$ & 0.17 & .47 \\
Mother & $0.47^{*}$ & 0.08 & .22 & & $0.30^{*}$ & $0.00^{\mathrm{a}}$ & $.00^{\mathrm{b}}$ \\
Child & $0.61^{*}$ & 0.02 & .59 & & $0.46^{*}$ & 0.11 & .06 \\
\hline
\end{tabular}

Note. $\quad N=76$. TRIM $=$ transgression-related interpersonal motivation; PTRIM $=$ Perceived TRIM.

${ }^{a}$ Negative variance estimate constrained to zero. ${ }^{\mathrm{b}}$ Reciprocity correlation set to zero due to absence of partner variance.

$* p<.05$. Significance tests are one-tailed for variance estimates; two-tailed for correlations.

RMSEA $=.00]$ and PTRIM ratings $\left[\chi^{2}(18)=11.19, p>.05\right.$, $\mathrm{CFI}=1.00, \mathrm{RMSEA}=.00](N=228$ for each $)$.

Individual level: Forgivingness. Table 6 reports individuallevel variance estimates and reciprocity correlations. As in Study 1 , evidence for individual differences in forgivingness based on self-reports (TRIM actor variance) was strong. Unlike Study 1, however, evidence from other reports (PTRIM partner variance) is lacking. When partner variance is negligible, this reflects a lack of consensus among raters (Kenny, 1994). In other words, for this sample, there was little agreement among family members about the forgivingness of fathers, mothers, or children.

Despite the lack of significant PTRIM partner variance, selfother agreement correlations (between estimated TRIM actor effects and PTRIM partner effects) were significant for fathers and children $(r \mathrm{~s}=.34$ and .28 , respectively, $p \mathrm{~s}<.05)$, but not for mothers $(r=.10, p>.05)$. Thus, there is evidence of modest concurrence between fathers' and children's self-ratings of forgivingness and those of other family members. ${ }^{3}$

Individual level: Forgivability. Similarly, individual differences on forgivability were evident in self-reports (PTRIM actor variance), but evidence from other reports (TRIM partner variance) was mixed. TRIM partner variance was significant for fathers (unlike Study 1), but not for mothers or children (also unlike Study 1). Thus, mothers and children agreed about whether fathers were forgivable or unforgivable, but there was no consensus among other family members about forgivability of mothers or children. Self-other agreement correlations for forgivability for fathers, mothers, and children were all significant $(r s=.33, .25$, and .40 , respectively, $p s<.05$ ), indicating that persons who believed they tended to be forgiven by others in the family actually were (see Footnote 3).

Individual level: Reciprocity. As indicated in Table 6, reciprocity correlations at the individual level (i.e., correlations between each family member's actor and partner effects) were significant for fathers' TRIM ratings, but not for their PTRIM ratings, and not for mothers or children on the TRIM or PTRIM. This is not surprising, given that partner variance was nonsignificant except for fathers' TRIM ratings. When there is little or no partner variance, actor-partner (i.e., generalized reciprocity) correlations are expected to be modest or nonexistent.

Relationship level: Variance estimates. Table 7 shows relationship variance estimates and dyadic reciprocity correlations for TRIM and PTRIM ratings for each of the six dyads. For TRIMs, relationship variance was significant for both parent-parent dyads
(MF and FM) and also for CF dyads. Thus, in each of these dyads, motivation to forgive is based in part on unique relationship-level factors (different from the forgiver's actor effect and the transgressor's partner effect).

For PTRIM ratings, relationship variance was significant for all dyads except FC. Thus, when family members were in the transgressor role, their experience of others' motivation to forgive was determined in part by unique (relational) factors.

Self-other agreement correlations for relationship effects were significant and substantial for all dyads ( $r$ s ranged from .59 to .65; $p s<.001)$, indicating that when persons felt uniquely forgiving toward a particular family member, that family member also tended to perceive them as uniquely forgiving toward her or him.

Relationship level: Reciprocity. As shown in Table 7, dyadic reciprocity correlations (i.e., correlations between two corresponding relationship effects) did not reach statistical significance (all $p \mathrm{~s}>.05)$, although dyadic reciprocity was positive and marginally significant $(p<.10)$ for parents' TRIMs toward their spouses. That is, husbands who were uniquely willing to forgive their wives (controlling for the relevant actor and partner effects) were also uniquely forgiven by them, and vice versa. The large negative reciprocity correlations for father-child and mother-child TRIMs should not be interpreted as a substantive finding; each represents a spurious correlation between two variance components (e.g., MC and CM relationship variance), neither of which differed significantly from zero.

Percentage of variance (by dyads). Figures 4 and 5 show the percentage of construct variance attributable to actor, partner, and relationship for TRIM and PTRIM ratings, respectively. Variance partitioning for TRIM ratings is similar to that in Study 1, with three exceptions. First, there is substantial partner variance in ratings of fathers (30\% of TRIM variance in MF and CF dyads) in the Study 2 sample, whereas in Study 1 there was no evidence of consensus in mothers' and children's ratings of fathers' forgivability (i.e., $0 \%$ of TRIM variance for these dyads was attributable to

\footnotetext{
${ }^{3}$ It may seem surprising that self-other agreement correlations can be significant in the absence of significant partner variance. This likely reflects confounding of individual effect estimates (computed using Warner et al.'s, 1979, approach) with dyadic variance. Thus, when selfother agreement is computed at the individual level, it is confounded to some extent with dyadic self-other agreement. We are indebted to Dave Kenny (personal communication) for this suggestion.
} 
Table 7

Relationship-Level Variance Estimates and Dyadic Reciprocity Correlations, Study 2

\begin{tabular}{llcccr}
\hline & \multicolumn{2}{c}{ TRIM } & & \multicolumn{2}{c}{ PTRIM } \\
\cline { 2 - 3 } \cline { 5 - 6 } Dyad & $\begin{array}{c}\text { Relationship } \\
\text { variance }\end{array}$ & $\begin{array}{c}\text { Dyadic } \\
\text { reciprocity }\end{array}$ & & $\begin{array}{c}\text { Relationship } \\
\text { variance }\end{array}$ & $\begin{array}{c}\text { Dyadic } \\
\text { reciprocity }\end{array}$ \\
\hline FM & $0.55^{*}$ & $0.46 \dagger$ & & $0.80^{*}$ & 0.04 \\
FC & 0.03 & $-1.00^{\mathrm{a}}$ & & 0.08 & -0.53 \\
MF & $0.52^{*}$ & $0.46 \dagger$ & & $0.92^{*}$ & 0.04 \\
MC & 0.16 & $-1.00^{\mathrm{a}}$ & & $0.65^{*}$ & 0.04 \\
$\mathrm{CF}$ & $0.28^{*}$ & $-1.00^{\mathrm{a}}$ & & $0.57^{*}$ & -.53 \\
$\mathrm{CM}$ & 0.05 & $-1.00^{\mathrm{a}}$ & & $0.57^{*}$ & .04 \\
\hline
\end{tabular}

Note. $\quad N=76$. TRIM $=$ transgression-related Interpersonal Motivation; PTRIM = Perceived TRIM; FM = father's ratings of mother; FC = father's ratings of child; $\mathrm{MF}=$ mother's ratings of father; $\mathrm{MC}=$ mother's ratings of child; $\mathrm{CF}=$ child's ratings of father; $\mathrm{CM}=$ child's ratings of mother.

${ }^{\text {a }}$ Estimated reciprocity correlation out of range, rounded.

$* p<.05 . \dagger p<.10$ (significance tests are one-tailed for variance estimates and two-tailed for correlations).

partner effects). Second, there is little evidence of consensus in ratings of children (less than 5\% of TRIM variance in FC and MC dyads was partner variance) in Study 2, whereas this consensus was strongly evident in Study 1(more than $25 \%$ of variance for these dyads was child partner variance). Third, relationship vari- ance is important not just for TRIM spouse ratings, but also for MC and CF dyads in Study 2 (approximately 20\%-25\% of variance for each of these dyads in Study 2, compared with less than $10 \%$ in Study 1). We consider the import of these discrepant findings in the Discussion section.

Differences in the relative partitioning of PTRIM construct variance (comparing Figures 3 and 5) are more striking. Although actor variance is still important (particularly for ratings by fathers and children), relationship variance now predominates in all but one dyad (FC). Relationship variance accounted for a median of $55 \%$ of PTRIM variance in Study 2, compared with $20 \%$ in Study 1. Partner variance, which was a significant determinant of PTRIM ratings in Study 1 (median of $15 \%$ to $20 \%$ variance accounted for), is all but nonexistent in Study $2(m d n=5 \%)$, indicating a lack of consensus between any two family members about the forgivingness of the third.

\section{Dyadic Correlates of Unique TRIMs and PTRIMs}

To determine whether dyadic trust and closeness predicted unique TRIMs and PTRIMs, even after controlling for transgression severity, we examined the associations of these three predictors with our two dependent variables using hierarchical regression analyses. Transgression severity was entered as Block 1 of the hierarchical regression, with trust and closeness entered as Block 2. The $F$ test for the change in $R^{2}$ upon entry of the Block 2

Study 2 TRIM Variance Partitioning (by Dyad)

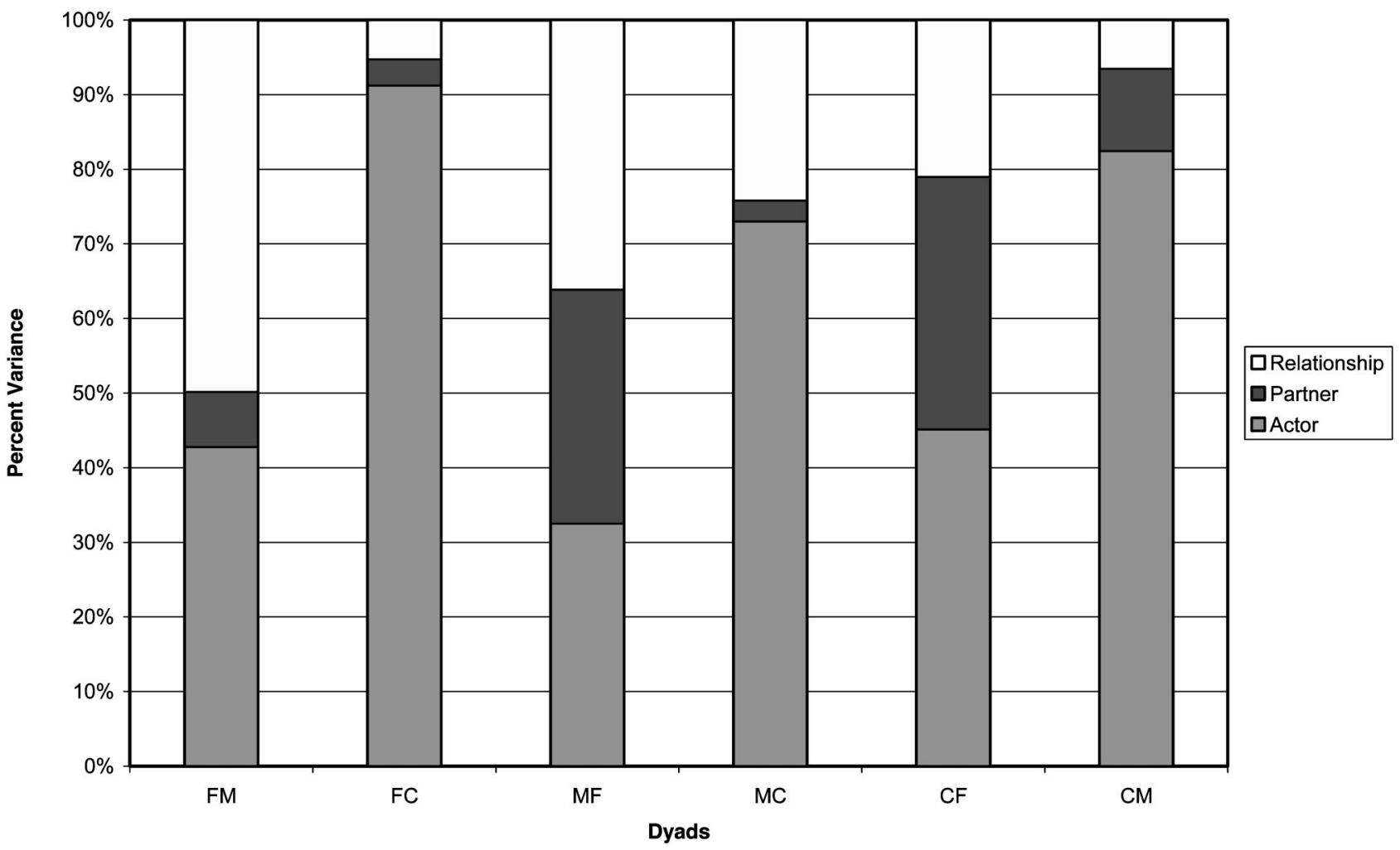

Figure 4. Percentage of variance in Study 2 TRIMs attributable to actor, partner, and relationship effects, by dyad. TRIMs $=$ transgression-related interpersonal motivations. 
Study 2 PTRIM Variance Partitioning (by Dyad)

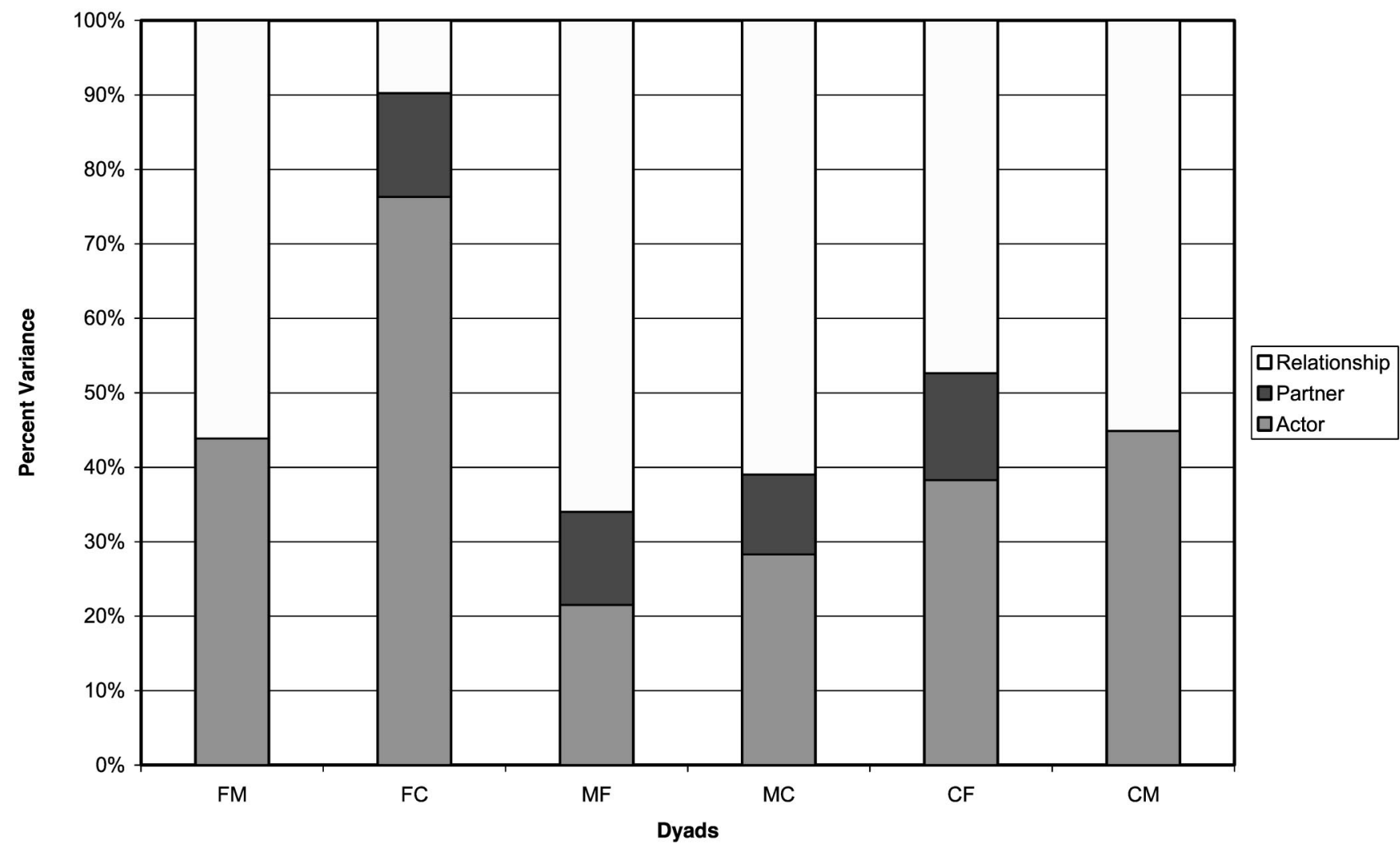

Figure 5. Percentage of variance in Study 2 PTRIMs attributable to actor, partner, and relationship effects, by dyad. PTRIMs = perceived transgression-related interpersonal motivations.

predictors provided a test of our third set of hypotheses for each dyad.

Regression results were similar for TRIM and PTRIM for most dyads (see Table 8). Transgression severity was a strong predictor of TRIMs, as expected. $R^{2}$ for Block 1 ranged from $.11(\mathrm{CM})$ to .31 (FM), all $p$ s $<.05$. Dyadic trust and closeness were entered as Block 2, and predicted significant incremental variance in unique TRIMs toward fathers (i.e., MF and CF dyads), with a marginally significant association $(p<.10)$ for MC dyads as well. For all three dyads, dyadic trust was significantly associated with unique TRIMs after controlling for severity and closeness; for no dyads was the association between closeness and unique TRIMs significant. (Trust and closeness were strongly correlated here-median $r=.63$ for 6 dyads-so it is not surprising that only one of these two predictors emerged as significant in each analysis.)

The pattern of findings for unique PTRIMs is similar to that for TRIMs: For all dyads (and especially for dyads involving the father as perceiver), unique perceptions of partner forgivingness are significantly explained by the typical severity of the partner's transgressions toward the perceiver. This is in part a function of reciprocity in transgression severity ratings: Congruence correlations (e.g., FM with MF) for severity ratings were $r=.56, .30$, and $.10 ; p \mathrm{~s}=.00, .01$, and .41 , respectively, for parent, father-child, and mother-child ratings. More important, trust and closeness predicted significant incremental variance in PTRIM relationship effects only for MC and MF dyads. (In both cases, trust, but not closeness, contributed uniquely to the prediction of PTRIM relationship effects.)

\section{Discussion}

Replicating the results of Study 1, the present study provided strong evidence for consistent individual differences in both forgivingness and forgivability based on self-ratings (i.e., TRIM and PTRIM actor effects). Evidence based on other ratings (i.e., TRIM and PTRIM partner variance), however, was absent except for fathers on the TRIM. There was significant consensus among mothers and children in these families about the forgivability of fathers, accounting for about $30 \%$ of the variance in TRIM ratings in each of these dyads (MF and $\mathrm{CF}$ ). The importance of relationship-specific effects was greater for some dyads than others, with parent-parent dyads showing the largest impact of relational factors for TRIM ratings (which accounted for about $50 \%$ of TRIM variance for FM dyads and $38 \%$ for MF dyads). A striking finding in Study 2 was the predominance of relationship variance in PTRIM ratings for these families: Relationship variance made up more than $50 \%$ of the total variance in PTRIM ratings for all dyads except FC. Thus, Study 2 broadly corroborated the findings of Study 1 concerning the importance of all three factors (forgivingness, forgivability, and relationship effects) as contributors to 
Table 8

Summary of Results From Hierarchical Regressions Predicting TRIM and PTRIM Relationship Effects From Relational Variables, Study 2

\begin{tabular}{|c|c|c|c|c|c|c|c|c|c|c|c|c|}
\hline \multirow{3}{*}{$\begin{array}{l}\text { Dyad and } \\
\text { block }\end{array}$} & \multicolumn{6}{|c|}{ TRIM } & \multicolumn{6}{|c|}{ PTRIM } \\
\hline & \multirow[b]{2}{*}{$\Delta R^{2}$} & \multirow[b]{2}{*}{$F^{\mathrm{a}}$} & \multirow[b]{2}{*}{$p$} & \multicolumn{3}{|c|}{$\beta$} & \multirow[b]{2}{*}{$\Delta R^{2}$} & \multirow[b]{2}{*}{$F^{\mathrm{a}}$} & \multirow[b]{2}{*}{$p$} & \multicolumn{3}{|c|}{$\beta$} \\
\hline & & & & SEV & TRU & CLO & & & & SEV & TRU & CLO \\
\hline FM Block 1 & .31 & 32.82 & .00 & $-.55 * *$ & & & .33 & 37.08 & .00 & $-.58 * *$ & & \\
\hline Block 2 & .01 & 0.52 & .59 & $-.53 * *$ & -.09 & .11 & .01 & 0.46 & .63 & $-.53 * *$ & .07 & .04 \\
\hline FC Block 1 & .22 & 20.73 & .00 & $-.47 * *$ & & & .17 & 14.98 & .00 & $-.41 * *$ & & \\
\hline Block 2 & .04 & 1.86 & .16 & $-.39 * *$ & -.03 & .23 & .01 & 0.54 & .59 & $-.37 *$ & .05 & .08 \\
\hline MF Block 1 & .19 & 17.29 & .00 & $-.44 * *$ & & & .13 & 10.86 & .00 & $-.36^{*}$ & & \\
\hline Block 2 & .12 & 6.33 & .00 & -.17 & $.34 *$ & .13 & .10 & 4.38 & .02 & -.14 & $.38^{*}$ & .00 \\
\hline MC Block 1 & .16 & 13.71 & .00 & $-.40 * *$ & & & .21 & 19.83 & .00 & $-.46 * *$ & & \\
\hline Block 2 & .05 & 2.47 & .09 & $-.28 *$ & $.33^{*}$ & -.14 & .07 & 3.30 & .04 & $-.35^{*}$ & $.37 *$ & -.18 \\
\hline CF Block 1 & .19 & 16.80 & .00 & $-.43 * *$ & & & .14 & 12.51 & .00 & $-.38 *$ & & \\
\hline Block 2 & .07 & 3.31 & .04 & $-.26^{*}$ & $.38^{*}$ & -.18 & .04 & 1.94 & .15 & $-.32 *$ & .23 & $-.24 \dagger$ \\
\hline CM Block 1 & .11 & 8.66 & .00 & $-.32 *$ & & & .06 & 4.44 & .04 & $-.24 *$ & & \\
\hline Block 2 & .01 & 0.29 & .75 & $-.32 *$ & -.06 & .10 & .00 & 0.07 & .93 & $-.25^{*}$ & -.01 & -.04 \\
\hline
\end{tabular}

Note. $\quad$ TRIM $=$ transgression-related interpersonal motivation; PTRIM $=$ perceived TRIM; SEV = severity of past transgressions; CLO = closeness; $\mathrm{TRU}=$ trust; FM = father's ratings of mother; FC = father's ratings of child; $\mathrm{MF}=$ mother's ratings of father; $\mathrm{MC}=$ mother's ratings of child; $\mathrm{CF}=$ child's ratings of father; $\mathrm{CM}=$ child's ratings of mother. Boldface $p$ values highlight the blocks in which predictors accounted for significant incremental variance in criterion scores.

${ }^{\mathrm{a}}$ For Block 1 (SEV entered), $d f \mathrm{~s}=1,74$ or 1, 75; for Block 2 (TRU, CLO entered), $d f \mathrm{~s}=2,72$ or 2, 73.

$* p<.05$. $* * *<<.001 . \dagger p<.10$, two-tailed.

forgiveness motivations in relationships. In the General Discussion section, we consider differences in the relative importance of these factors across dyads.

Evidence of self-other agreement was strongest at the dyadic level in Study 2. Indeed, significant self-other agreement correlations at the individual level, in the absence of significant TRIM or PTRIM partner variance, are suspect, and likely reflect confounding with dyadic agreement (see footnote 3). In both Studies 1 and 2, evidence of agreement was strongest at the dyadic level: Persons who rated themselves as uniquely forgiving toward a particular partner tended to be seen that way by the partner, and persons who experienced being uniquely forgiven by a particular partner also tended to be rated as forgivable by that partner.

As in Study 1, we also considered whether TRIMs and PTRIMs were reciprocated, at both the individual and dyadic levels. Because partner variance was less prominent in Study 2 (except for fathers' TRIM ratings), it is not surprising that generalized reciprocity correlations were only significant for father TRIMs. Dyadic reciprocity was marginally significant for parent-parent TRIMs, indicating that TRIM relationship effects, which showed significant variance for both FM and MF dyads, tend to be positively reciprocated.

Only dyadic predictors of forgiveness motivation were examined in Study 2. Again consistent with Study 1, a specific, conflictrelated variable (ineffective arguing in Study 1 and typical transgression severity in Study 2) was significantly predictive of unique TRIMs and PTRIMs for all dyads. Thus, both unique willingness to forgive a relationship partner and unique perceptions that that relationship partner is forgiving toward the self were predicted by typical conflict experiences in that relationship, including typical communication processes during arguments (Study 1) and typical hurtfulness of interpersonal transgressions (Study 2). More global indicators of relationship quality (i.e., trust) also added incremen- tally to the prediction of unique TRIMs and PTRIMs for some but not all dyads in both Studies 1 and 2 .

Unlike past studies (McCullough et al., 1998), dyadic closeness ratings were not predictive of forgiveness in Study 2. This may reflect moderation of the closeness-forgiveness association by relationship type. McCullough et al. studied the offenders selected by participants (most were romantic partners or same-age friends). Closeness may be a more important predictor of forgiveness in peer relationships than family relationships, perhaps as a function of restricted range in the latter context. A second plausible explanation is that the closeness-forgiveness association was attenuated in Study 2 by the inclusion of correlated predictors (median closeness-severity $r=-.37$ and median closeness-trust $r=.62$ across six dyads).

\section{General Discussion}

The tension between intrapersonal and interpersonal conceptions of forgiveness is exemplified by McCullough, Pargament, and Thoresen's (2000) need to straddle this line in setting the stage for a compendium of scholarly essays on forgiveness theory, research, and practice. McCullough et al.'s "minimalist" working definition stated that forgiveness consists of "intraindividual prosocial change toward a perceived transgressor that is situated within a specific interpersonal context" (p. 9). The acknowledgment that situational and interpersonal factors, as well as stable intrapersonal propensities, figure as key determinants of forgiveness motivations is in keeping with the broad consensus that behavior is a function of both person and situation (Ross \& Nisbett, 1991)

Generalizability analyses are well suited to exploring the relative importance of intra- and interpersonal determinants of forgiveness motivations (McCullough \& Hoyt, 2002). In the present 
studies, we used a specialized application of generalizability theory, the SRM, in which actor and especially partner variance indicate the importance of consistent motives or behaviors on the part of transgressor or victim, whereas relationship variance indicates the importance of dyadic factors in determining forgiveness motives. Our findings shed light on the relative contributions of victim forgivingness, offender forgivability, and relationship effects to forgiveness in family relationships, and provide support for a transactional model of forgiveness motives in families. In addition, our findings suggest differences in both the correlates and relative importance of these three determinants of forgiveness motives for different roles and relationships within the family.

\section{Comparison of Findings From Studies 1 and 2}

Several key findings were consistent across samples: (a) importance of all three SRM components (actor, partner, and relationship) for understanding forgiveness, (b) differential importance of these components for different family roles and dyads (e.g., parent-parent dyads show greater evidence of relationship variance in both TRIMs and PTRIMs), (c) greater importance of relationship variance for PTRIMs as compared with TRIMs, (d) concurrence between other-ratings and self-ratings of forgivingness and forgivability, and (e) relatively modest evidence of reciprocity in forgiving.

\section{Reciprocity in Forgiving}

The lack of consistent evidence for reciprocity may be seen as somewhat surprising. At the individual level, we intuitively expect that a person who is typically forgiving toward others will also be forgiven by others when the shoe is on the other foot. In Table 4, personality correlates tend to be in the same direction for forgiveness and forgivability, suggesting that attributes that make a person forgivable also tend to make her or him forgiving, and vice versa. Why then is consistent evidence of generalized reciprocity not found in Tables 2 and 6? On close inspection, the evidence is not as inconsistent as it first appears. Because actor-partner covariance is a function of variance in actor and partner effects, we do not expect significant reciprocity correlations at the individual level unless both actor and partner variance are statistically significant. Although actor variance was uniformly significant for TRIMs and PTRIMs in both studies, only 5 of the 12 partner variance estimates in Tables 2 and 6 were significantly different from zero. Of the five corresponding reciprocity correlations, four were significant as well. This suggests that when there is consensus among other family members about a person's forgivingness (PTRIM partner variance) or forgivability (TRIM partner variance), generalized reciprocity is also likely to be observed.

Dyadic reciprocity examines the question of whether, controlling for a person's generalized tendency to forgive (or to elicit forgivingness from) others, this person's unique forgivingness (or forgivability) in a specific relationship is reciprocated by the partner. Although there is a considerable amount of research among romantic partners and married couples suggesting reciprocity of both positive and negative affect (e.g., Gleason, Iida, Bolger, \& Shrout, 2003; Gottman, 1979; Revenstorf, Vogel, Wegener, Halweg, \& Schindler, 1980), there is less evidence for reciprocity in parent-child dyads. (Indeed, as a reviewer of this article pointed out, there is some reason to expect-or hope - that parents will not reflexively reciprocate children's negative affective reactions.) Dyadic reciprocity in SRM requires relationship variance on both sides of the dyad (e.g., FM and MF). When this condition was met (in Study 2 TRIMs), the dyadic reciprocity correlation was substantial and marginally significant, suggesting that relationshipspecific forgivingness, when present, may indeed be reciprocated.

\section{Between-Sample Differences}

Differences in findings between Studies 1 and 2 were most obvious in the patterns of variance partitioning depicted in Figures $2-5$. For the families in Study 2, TRIMs and especially PTRIMs were to a greater extent a function of relationship effects, with less of a role for both actor and partner effects, compared with the Study 1 families. For example, for child ratings (CF and CM dyads), the preponderance of the variance in both TRIMs and PTRIMs in Study 1 is attributable to actor effects, in contrast to Study 2, in which there is a greater role for relationship and sometimes partner variance. In other words, children in Study 1 were quite consistent in their motives toward and perceptions both parents, whereas Study 2 children reported rather different TRIMs and PTRIMs with respect to mothers and fathers. Because the two samples differed both by culture (United States vs. Great Britain) and gender (all girls vs. boys and girls), the source of these differences in patterns of forgiveness motives and perceptions is unclear.

\section{Limitations}

In interpreting the findings reported here, it is helpful to keep in mind three features of these studies that affect the meaning of the SRM variance components. First, only family relationships were studied, so variance estimates are not expected to generalize to broader interpersonal contexts. For example, given the median TRIM actor variance for fathers of .47 , it might be concluded that fathers' forgiveness motivation is $47 \%$ attributable to stable dispositional tendencies to forgive others. Such interpretations should be qualified, however, in that people may well be more consistent in their forgivingness within the family than they are in relationships in general. Thus, actor variance estimates in this study might reasonably be regarded as an upper bound on the proportion of variance in forgiveness motives (or perceptions of others' motives) that is attributable to stable personality traits.

Second, there is an asymmetry inherent in the study of threeperson family groups, in that such groups (in this study) were composed of two parents and one child. The consequences of this asymmetry are most obvious in considering partner variance estimates. In the case of children, partner variance reflects agreement among parents about their child's forgivability or forgivingness. In the case of a parent, partner variance reflects agreement between spouse and child. If parents agree with one another (in judgments about their child) more than they agree with their child (in judgments about their spouse), partner variance will be larger for children than for parents when SRM is applied to three-person families. By the same token, actor variance for children reflects consistency in responding to both parents, whereas accuracy for a parent reflects consistency in responding to spouse and child. This asymmetry leads to somewhat different interpretations of variance components for children than for parents in the three-person family 
design, and sharpens interest in the source of differences for the New York and Wales samples (e.g., for child actor variance).

Third, by studying recollections of general forgiveness rather than forgiveness for specific transgressions, we in essence treat as fixed effects those features of specific hurtful incidents (such as severity, intentionality, and contrition) that are known to be important predictors of forgivingness. Most common measures of forgiveness are transgression specific (McCullough, Hoyt, et al., 2000), and scores on these measures contain variance attributable to transgression severity (and victim attributions of transgressor intention and contrition) as well as the forgivingness, forgivability, and relationship-specific components studied here. Future research including multiple specific transgressions for each dyad (Hoyt \& McCullough, 2005) will provide a more complete picture of the determinants of forgiveness for a particular transgression, and will further highlight the limited importance of dispositional forgivingness suggested here and elsewhere (McCullough \& Hoyt, 2002).

\section{Conclusions}

The data reported in this study are among the first to address empirically the level of analysis best suited to conceptualizing motivations that drive responses to conflict in families. Our findings indicate that both individual (actor and partner effects) and dyadic levels of analysis account for substantial variance in actual and perceived forgiveness. Responses to transgressions are partly dispositional (in that people demonstrate consistent patterns of forgivingness across relationship partners), but also partly a function of the relationship and of the partner's forgivability. Moreover, the relative importance of these three determinants differed by family role and relationship type. We conclude that the study of forgiveness needs to be embedded in more complex psychosocial contexts. This conclusion has important theoretical, methodological, and applied implications.

At the theoretical level, there is a clear need for models that integrate the individual and dyadic factors in mechanisms posited to initiate and sustain conflict in close relationships. Developmental models hold special promise here, as a framework for examining the hypothesized reciprocal nature of forgiveness motivations. Longitudinal studies are necessary to test the notion that patterns of reactions to transgressions evolve over time, with initial actual and perceived responses fueling future expectations about how conflict will be managed in a relationship. In addition, theories of conflict in heterosexual relationships need to consider evidence for differential contextual sensitivity on the part of men and women (see Fincham, Beach, Harold, \& Osborne, 1997).

As regards methodology, researchers studying conflict in close relationships should take the multiple determinants of TRIMs into account when choosing a research design. Multiple measures, taken from several perspectives, are clearly desirable for understanding both individual and dyadic responses to conflict (Hoyt \& McCullough, 2005). Researchers also need to select analytical techniques capable of modeling the interdependence of partners' forgiveness motivations (Kenny, 1996; Sameroff \& MacKenzie, 2003). These techniques are especially attractive in that they are tailored to the research question and level of analysis, and are capable of addressing reciprocal causation in close relationships.

Finally, from an applied standpoint, clinicians have long targeted conflict as an intervention focus in work with couples and families. Forgiveness-based therapies (DiBlasio, 1998; Gordon,
Baucom, \& Snyder, 2000; Worthington, 1998) addressing both intra- and interpersonal determinants of responses to transgressions offer a promising strategy for addressing marital and family conflict. Our findings encourage clinicians as well as researchers to conceptualize conflict reactions as embedded in relational contexts, and support efforts to address family patterns of conflict systemically, rather than focusing exclusively on the individual level of intervention.

\section{References}

Alicke, M. D. (2000). Culpable control and the psychology of blame. Psychological Bulletin, 126, 556-574.

Ashton, M. C., Paunonen, S. V., Helmes, E., \& Jackson, D. N. (1998). Kin altruism, reciprocal altruism, and the Big Five personality factors. Evolution and Human Behavior, 19, 243-255.

Beach, S. R. H., Fincham, F. D., \& Katz, J. (1998). Marital therapy in the treatment of depression: Toward a third generation of therapy and research. Clinical Psychology Review, 18, 635-661.

Bentler, P. M. (1995). EQS structural equations program manual. Encino, CA: Multivariate Software.

Block, J. H., \& Block, J. (1980). The role of egocontrol and ego-resiliency in the organization of behavior. In W. A. Collins (Ed.), Minnesota Symposium on Child Psychology (Vol. 13, pp. 39-101). Hillsdale, NJ: Erlbaum.

Bradbury, T. N., Fincham, F. D., \& Beach, S. R. H. (2000). Research on the nature and determinants of marital satisfaction: A decade in review. Journal of Marriage and the Family, 62, 964-980.

Brody, G. H., Stoneman, Z., \& McCoy, J. K. (1994). Forecasting sibling relationships in early adolescence from child temperaments and family processes in middle childhood. Child Development, 65, 771-784.

Chen, F., Bollen, K. A., Paxton, P., Curran, P. J., \& Kirby, J. B. (2001). Improper solutions in structural equation models: Causes, consequences, and strategies. Sociological Methods and Research, 29, 468-508.

Cobb, R. J., Davila, J., \& Bradbury, T. N. (2001). Attachment security and marital satisfaction: The role of positive perceptions and social support. Personality \& Social Psychology Bulletin, 27, 1131-1143.

Cook, W. L. (1993). Interdependence and the interpersonal sense of control: An analysis of family relationships. Journal of Personality and Social Psychology, 64, 587-601.

Cook, W. L. (2000). Understanding attachment security in family context. Journal of Personality and Social Psychology, 78, 285-294.

Cook, W. L., Kenny, D. A., \& Goldstein, M. J. (1991). Parental affective style risk and the family system: A social relations model analysis. Journal of Abnormal Psychology, 100, 492-501.

Côté, S., \& Moskowitz, D. S. (1998). On the dynamic covariation of interpersonal behavior and affect: Prediction from Neuroticism, Extraversion, and Agreeableness. Journal of Personality and Social Psychology, 75, 1032-1046.

Cotterell, N., Eisenberger, R., \& Speicher, H. (1992). Inhibiting effects of reciprocation wariness on interpersonal relationships. Journal of Personality and Social Psychology, 62, 658-668.

Darby, B. W., \& Schlenker, B. R. (1982). Children's reactions to apologies. Journal of Personality and Social Psychology, 4, 742-753.

Davies, P. T., \& Cummings, E. M. (1994). Marital conflict and child adjustment: An emotional security hypothesis. Psychological Bulletin, 116, 387-411.

Davila, J., \& Bradbury, T. N. (1998). Psychopathology and the marital dyad. In L. L'Abate (Ed.), Family psychopathology (pp. 127-157). New York: Guilford Press.

Derryberry, D., \& Reed, M. A. (1994). Temperament and attention: Orienting toward and away from positive and negative signals. Journal of Personality and Social Psychology, 66, 1128-1139.

DiBlasio, F. A. (1998). The use of decision-based forgiveness intervention 
within intergenerational family therapy. Journal of Family Therapy, 20, 77-94.

Epstein, N., Baucom, D. H., \& Rankin, L. A. (1993). Treatment of marital conflict: A cognitive-behavioral approach. Clinical Psychology Review, $13,45-57$.

Erel, O., \& Burman, B. (1995). Interrelatedness of marital relations and parent-child relations: A meta-analytic review. Psychological Bulletin, $118,108-132$.

Fincham, F. D. (2000). The kiss of the porcupines: From attributing responsibility to forgiving. Personal Relationships, 7, 1-23.

Fincham, F. D. (2001). Attributions and close relationships: From balkanization to integration. In G. J. Fletcher \& M. Clark (Eds.), Blackwell handbook of social psychology (pp. 3-31). Oxford, England: Blackwell Press.

Fincham, F. D., \& Beach, S. R. (2002). Forgiveness in marriage: Implications for psychological aggression and constructive communication. Personal Relationships, 9, 239-251.

Fincham, F. D., Beach, S. R. H., Harold, G. T., \& Osborne, L. N. (1997). Marital satisfaction and depression: Different causal relationships for men and women? Psychological Science, 8, 351-357.

Fincham, F. D., Harold, G. T., \& Gano-Phillips, S. (2000). The longitudinal association between attributions and marital satisfaction: Direction of effects and role of efficacy expectations. Journal of Family Psychology, $14,267-285$.

Gleason, M. E. J., Iida, M., Bolger, N., \& Shrout, P. E. (2003). Daily supportive equity in close relationships. Personality and Social Psychology Bulletin, 29, 1036-1045.

Gordon, K. C., Baucom, D. H., \& Snyder, D. K. (2000). The use of forgiveness in marital therapy. In M. E. McCullough \& K. I. Pargament (Eds.), Forgiveness: Theory, research, and practice (pp. 203-227). New York: Guilford Press.

Gottman, J. M. (1979). Marital interaction: Experimental investigations. New York: Academic Press.

Gottman, J. M. (1994). What predicts divorce? The relationship between marital processes and marital outcomes. Hillsdale, NJ: Erlbaum.

Gottman, J. M. (1998). Psychology and the study of the marital processes. Annual Review of Psychology, 49, 169-197.

Grych, J. H., \& Fincham, F. D. (1990). Marital conflict and children's adjustment: A cognitive-contextual framework. Psychological Bulletin, 108, 267-290.

Gunthert, K. C., Cohen, L. H., \& Armeli, S. (1999). The role of Neuroticism in daily stress and coping. Journal of Personality and Social Psychology, 77, 1087-1100.

Hoyt, W. T., \& McCullough, M. E. (2005). Issues in the multimodal measurement of forgiveness. In E. L. Worthington Jr. (Ed.), Handbook of forgiveness (pp. 109-123). New York: Brunner-Routledge.

John, O. P. (1990). The "Big Five" factor taxonomy: Dimensions of personality in natural language and in questionnaires. In L. A. Pervin (Ed.), Handbook of personality: Theory and research (pp. 66-100). New York: Guilford Press

Karremans, J. C., Van Lange, P. A. M., Ouwerkerk, J. W., \& Kluwer, E. S. (2003). When forgiving enhances psychological well-being: The role of interpersonal commitment. Journal of Personality and Social Psychology, 84, 1011-1026.

Kashy, D. A., \& Kenny, D. A. (1990). Analysis of family research designs: A model of interdependence. Communication Research, 17, 462-482.

Kearns, J. N., \& Fincham, F. D. (2005). Victim and perpetrator accounts of interpersonal transgressions: Self-serving or relationship-serving biases? Personality and Social Psychology Bulletin, 31, 321-333.

Kenny, D. A. (1994). Interpersonal perception: A social relations analysis. New York: Guilford Press

Kenny, D. A. (1996). The design and analysis of social-interaction research. Annual Review of Psychology, 47, 59-86.

Kenny, D. A., \& LaVoie, L. (1984). The social relations model. In L.
Berkowitz (Ed.), Advances in experimental social psychology (Vol. 18 , pp. 141-182). New York: Academic Press.

Kenny, D. A., \& Nasby, W. (1980). Splitting the reciprocity correlation. Journal of Personality and Social Psychology, 38, 249-256.

Kiecolt-Glazer, J. K., Malarkey, W. B., Chee, M., Newton, T., Cacioppo, J. T., et al. (1993). Negative behavior during marital conflict is associated with immunological down-regulation. Psychosomatic Medicine, 55, 395-409.

Kurdek, L. A. (1994). Areas of conflict for gay, lesbian, and heterosexual couples: What couples argue about influences relationship satisfaction. Journal of Marriage and the Family, 56, 923-934.

Leary, T. (1957). The interpersonal diagnosis of personality. New York: Ronald.

Margolin, G., Christensen, A., \& John, R. S. (1996). The continuance and spillover of everyday tensions in distressed and nondistressed families. Journal Family Psychology, 10, 304-321.

Markey, P. M., Funder, D. C., \& Ozer, D. J. (2003). Complementarity of interpersonal behaviors in dyadic interactions. Personality and Social Psychology Bulletin, 29, 1082-1090.

McCullough, M. E. (2001). Forgiveness: Who does it and how do they do it? Current Directions in Psychological Science, 10, 194-197.

McCullough, M. E., Bellah, C. G., Kilpatrick, S. D., \& Johnson, J. L. (2001). Vengefulness: Relationships with forgiveness, rumination, wellbeing, and the Big Five. Personality and Social Psychology Bulletin, 27, 601-610.

McCullough, M. E., Fincham, F. D., \& Tsang, J.-A. (2003). Trajectories of forgiveness: The temporal unfolding of transgression-related interpersonal motivations. Journal of Personality and Social Psychology, 84, $540-557$.

McCullough, M. E., \& Hoyt, W. T. (2002). The forgiver in context: Personal and situational determinants of forgiveness. Personality and Social Psychology Bulletin, 28, 1556-1573.

McCullough, M. E., Hoyt, W. T., \& Rachal, K. C. (2000). What we know (and need to know) about assessing forgiveness constructs. In M. E. McCullough \& K. I. Pargament (Eds.), Forgiveness: Theory, research, and practice (pp. 65-88). New York: Guilford Press.

McCullough, M. E., Pargament, K. I., \& Thoresen, C. E. (2000). The psychology of forgiveness: History, conceptual issues, and overview. In M. E. McCullough \& K. I. Pargament (Eds.), Forgiveness: Theory, research, and practice (pp. 1-14). New York: Guilford Press.

McCullough, M. E., Rachal, K. C., Sandage, S. J., Worthington, E. L., Jr., Brown, S. W., \& Hight, T. L. (1998). Interpersonal forgiving in close relationships: II. Theoretical elaboration and measurement. Journal of Personality and Social Psychology, 75, 1586-1603.

McCullough, M. E., Worthington, E. L., Jr., \& Rachal, K. C. (1997). Interpersonal forgiving in close relationships. Journal of Personality and Social Psychology, 73, 321-336.

Mullet, E., \& Girard, M. (2000). Developmental and cognitive points of view on forgiveness. In M. E. McCullough \& K. I. Pargament (Eds.), Forgiveness: Theory, research, and practice (pp. 111-132). New York Guilford Press.

Murphy, C. M., \& O'Leary, K. D. (1989). Psychological aggression predicts physical aggression in early marriage. Journal of Consulting and Clinical Psychology, 57, 579-582.

Owen, M. T., \& Cox, M. J. (1997). Marital conflict and the development of infant-parent attachment relationships. Journal Family Psychology, $11,152-164$.

Revenstorf, D., Vogel, B., Wegener, C., Halweg, K., \& Schindler, L. (1980). Escalation phenomena in interaction sequences: An empirical comparison in distressed and nondistressed couples. Behavior Analysis and Modification, 2, 97-116.

Ross, L., \& Nisbett, R. E. (1991). The person and the situation: Perspectives of social psychology. New York: McGraw-Hill.

Rusbult, C. E., \& Van Lange, P. A. M. (2003). Interdependence, interaction, and relationships. Annual Review of Psychology, 54, 351-375. 
Rusbult, C. E., Verette, J., Whitney, G. A., Slovik, L. F., \& Lipkus, I. (1991). Accommodation processes in close relationships: Theory and preliminary empirical evidence. Journal of Personality and Social Psychology, 60, 53-78.

Russell, D. W. (2002). In search of underlying dimensions: The use (and abuse) of factor analysis in Personality and Social Psychology Bulletin. Personality and Social Psychology Bulletin, 28, 1629-1646.

Sameroff, A. J., \& MacKenzie, M. J. (2003). Research strategies for capturing transactional models of development: The limits of the possible. Development and Psychopathology, 15, 613-640.

Saucier, G. (1994). Mini-markers: A brief version of Goldberg's unipolar big-five markers. Journal of Personality Assessment, 63, 506-516.

Stillwell, A. M., \& Baumeister, R. F. (1997). The construction of victim and perpetrator memories: Accuracy and distortion in role-based accounts. Personality and Social Psychology Bulletin, 23, 1157-1172.

Takaku, S., Weiner, B., \& Ohbuchi, K. I. (2001). A cross-cultural examination of the effects of apology and perspective taking on forgiveness. Journal of Language and Social Psychology, 20, 144-166.

Taylor, S. E., \& Repetti, R. L. (1997). What is an unhealthy environment and how does it get under the skin? Annual Review of Psychology, 48, 411-447.
Warner, R. M., Kenny, D. A., \& Stoto, M. (1979). A new round-robin analysis of variance for social interaction data. Journal of Personality and Social Psychology, 37, 1742-1757.

Wickrama, K. A. S., Lorenz, F. O., \& Conger, R. D. (1997). Parental support and adolescent physical health status: A latent growth-curve analysis. Journal of Health and Social Behavior, 38, 149-163.

Wickrama, K. A. S., Lorenz, F. O., Conger, R. D., \& Elder, G. H., Jr. (1997). Marital quality and physical illness: A latent growth curve analysis. Journal of Marriage and the Family, 59, 143-155.

Wieselquist, J., Rusbult, C. E., Foster, C. A., \& Agnew, C. R. (1999), Commitment, pro-relationship behavior, and trust in close relationships. Journal of Personality and Social Psychology, 77, 942-966.

Worthington, E. L. (1998). An empathy-humility-commitment model of forgiveness applied within family dyads. Journal of Family Therapy, 20, $59-76$.

Received March 2, 2004 Revision received November 4, 2004 Accepted November 5, 2004

\section{Instructions to Authors}

For Instructions to Authors, please visit www.apa.org/journals/psp and click on the "Instructions to Authors" link in the Journal Info box on the right. 